\title{
Two-Axis Laser-Induced Fluorescence of Singly-Charged Xenon inside a 6-kW Hall Thruster
}

\author{
Wensheng Huang ${ }^{*}$, Alec D. Gallimore ${ }^{\dagger}$, and Timothy B. Smith ${ }^{*}$ \\ Plasmadynamics and Electric Propulsion Laboratory, University of Michigan, Ann Arbor, MI 48109
}

\begin{abstract}
We present two-axis laser-induced fluorescence velocimetry measurements of the $5 d[4]_{7 / 2}$ $\rightarrow 6 \mathrm{p}[3]^{0}{ }_{5 / 2}$ transition for singly-charged xenon (Xe II) at $834.953 \mathrm{~nm}$ (vacuum) inside a 6kW Hall thruster. The spatial density of the data is higher near the wall than in the center of the channel to better capture the dynamics of the ions believed to be responsible for wall erosion. The thruster has a nominal operating discharge voltage of $300 \mathrm{~V}$ and anode mass flow rate of $20 \mathrm{mg} / \mathrm{s}$ and has been operated for $\sim 330$ hours prior to testing. It is operated under seven conditions spanning discharge voltages of 150-600 $\mathrm{V}$ and anode mass flow rates of 10-30 mg/s. The bulk velocity of the near-wall ion populations varies from 0.5 to $25 \mathrm{~km} / \mathrm{s}$ with an angle of incidence relative to the normal of the wall surface that varies from roughly 45 to 80 degrees. In general, the bulk velocity and angle of incidence is strongly correlated with the discharge voltage and weakly correlated with the anode mass flow rate. There is strong correlation between the axial locations where high energy (greater than few tens of eV) ions exist and where erosion is discernable in the channel profile.
\end{abstract}

\section{Introduction}

$\mathrm{A}^{\mathrm{s}}$ S Hall thruster technology becomes increasingly mature, more and more attention is being paid toward the prediction of thruster lifetime. This paper will focus on one of the primary Hall thruster life-limiting mechanism, the erosion of the channel wall. Modeling efforts have had some successes ${ }^{1-4}$ but the underlying physics of the erosion process is still not well understood. In particular, there is a lack of data regarding the bombarding particles responsible for eroding the channel wall. By performing experiments to study these particles, we can improve our predictive and design capabilities to enhance Hall thruster lifetime. In this paper, we will present a twoaxis laser-induced fluorescence (LIF) study of the ions, which are believed to be responsible for the majority of channel wall erosion, in a Hall thruster.

The process of erosion has been extensively studied in other plasma environments. In particular, works by Garnier, et al., ${ }^{5}$ Yamamura, ${ }^{6}$ and Zhang $^{7}$ have laid the foundation for modeling differential sputter yield as a function of the velocity and angle of the bombarding particle. Rubin, et al, are building on this foundation to create a comprehensive database for the bombardment of boron nitride (typical magnetic layer thruster wall material) by low-energy $(\sim 100 \mathrm{eV})$ xenon particles (typical Hall thruster propellant) ${ }^{8}$ At the moment, in order to find the velocity and angular distributions of the bombarding particles, one generally uses some form of modeling. In this paper, we will present an experimental approach to obtaining the mean velocity and direction of xenon ions, which are believed to cause the majority of wall erosion. Methods for extracting the velocity and angular distributions of the ions are then discussed.

Laser induced fluorescence (LIF) is an optical technique that can extract non-intrusive, species-specific, and spatially-resolved information from inside the discharge channel of a Hall thruster. Previous LIF studies inside of Hall thrusters have focused on single-axis studies due to the difficulty of extracting and processing multi-axis data from inside the thruster. ${ }^{9-11}$ One approach to obtaining two-axis LIF data is to use slots, sometimes filled with a transparent material to minimize disturbance to the local plasma. ${ }^{12}$ The approach we present here does not involve any modification to the thruster being examined. This approach is very similar to one of our previous LIF studies ${ }^{13}$ except for the addition of a second laser axis and modification to the collection optics to accommodate the new addition. The goal of this paper is to present our novel experimental approach and summarize the results that characterize the behavior of singly-charged xenon ion inside of the discharge channel of a 6-kW Hall thruster. We

\footnotetext{
${ }^{*}$ Ph. D. Candidate, Aerospace Engineering, davhuang@umich.edu, Student Member, AIAA.

${ }^{\dagger}$ Arthur F. Thurnau Professor, Aerospace Engineering, Alec.Gallimore@umich.edu, Fellow, AIAA.

* Lecturer, Aerospace Engineering, timsmith@umich.edu, Senior Member, AIAA.
} 
used the Xe II $5 \mathrm{~d}[4]_{7 / 2} \rightarrow 6 \mathrm{p}[3]^{\circ}{ }_{5 / 2}$ transition at $834.953 \mathrm{~nm}$ (vacuum) to excite the xenon ions and collected nonresonant fluorescence at $542 \mathrm{~nm}$ (vacuum). Due to a lack of published hyperfine structure constants for this transition, we used a method involving direct deconvolution of the hyperfine structures to remove the distortions due to hyperfine structure effects. ${ }^{14}$

\section{Theories}

This section lay out the theory underlying the extraction of velocity distribution functions (VDFs) from raw LIF spectra. For the remainder of this paper, all transition wavelengths are given in vacuum values and all intensities given in arbitrary units, a.u., unless otherwise specified. Note that any discussion of temperature is generally avoided as the plasma under study is not expected to be in thermal equilibrium given the discharge channel plasma conditions. For the most parts, full-width-at-half-maximum (FWHM) values are discussed instead.

\section{A. Principles of Laser-Induced Fluorescence Velocimetry}

LIF operates on the principle that when a particle (an atom or molecule) absorbs a photon, it will de-excite and emit another photon. Excited particles will de-excite by collision, spontaneous emission, or stimulated emission. Particles that spontaneously emit photons at the same energy as the absorbed photons are said to undergo resonant emission. Particles that emit photons at energies different from that of the absorbed photons are said to undergo nonresonant emission. This spontaneous emission, called fluorescence, radiates isotropically away from the particle.

To obtain the particle VDF via LIF, we take advantage of the Doppler shift. For a particle travelling at nonrelativistic speed, the shift in absorption frequency is proportional to the particle velocity component in the direction that the photon travels. The mathematical equation is given in Eq. (1)

$$
\frac{\Delta v}{v_{0}}=-\frac{\mathbf{v}}{c} \cdot \frac{\mathbf{k}}{|\mathbf{k}|}
$$

where $v_{0}$ is the photon frequency, $\Delta v$ is the shift in photon frequency from the perspective of the particle, $\mathbf{v}$ is the particle velocity, $\mathrm{c}$ is the speed of light, and $\mathbf{k}$ is the photon wave vector. By varying the frequency of the injected photons and comparing the intensity of the collected fluorescence, we can obtain the particle VDF along the injected photon wave vector.

In this experiment, light is injected at around $835 \mathrm{~nm}$ and non-resonant LIF is collected at $542.066 \mathrm{~nm}$. Figure 1 shows the transition diagram. Due to the nature of LIF, this experiment actually measures the VDF of the excited metastable state $5 \mathrm{~d}[4]_{7 / 2}$, which is assumed to have the same VDF as the entire ion population.

\section{B. Hyperfine Structure and Deconvolution}

Analysis of LIF data is complicated by the presence of broadening factors, which can distort and widen the raw data. For the Xe II $5 \mathrm{~d}[4]_{7 / 2} \rightarrow 6 \mathrm{p}[3]_{5 / 2}^{\circ}$ transition, a prominent broadening factor is the hyperfine structure. The hyperfine structure constants for the lower state of the Xe II $834.953 \mathrm{~nm}$ transition are not known. However, the hyperfine structure has been shown to be around $500 \mathrm{MHz}$ wide in photon frequency space. ${ }^{14}$ The FWHM of the average ion VDF in a Hall thruster typically varies from 1 to $10 \mathrm{~km} / \mathrm{s}$, which for this transition corresponds to about 1.2 to $12 \mathrm{GHz}$. Where the VDF is wide, the hyperfine structure will present a negligible broadening of the lineshape. Where the VDF is narrow, like in the plasma upstream of the acceleration zone, removal of hyperfine structure effect is important.

Natural (or lifetime) broadening, which is due to the Heisenberg

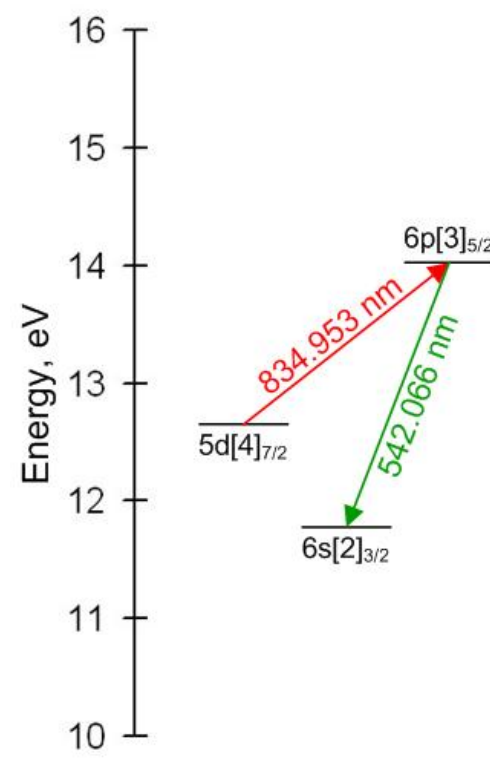

Figure 1. Transition diagram for Xe II LIF at $834.953 \mathrm{~nm}$. Wavelengths in vacuum. uncertainty principle, is also present. This effect broadens an absorption line into a Lorentzian function. The natural broadening effect is believed to be negligible compared to the hyperfine structure effect based on measurements at other xenon ion lines. Specifics of hyperfine structure and natural broadening theories can be found in Svanberg. ${ }^{15}$

Furthermore, external electric and magnetic fields can increase the number of hyperfine splittings. For the purpose of this experiment, we will try to avoid these distortions as much as possible. These externally influenced 
splittings depend on the direction and polarity of the injected laser beam. The electric field present in a typical Hall thruster is several orders of magnitude smaller than what is necessary to cause distortions, called the Stark effect. ${ }^{16}$ The magnetic field effect for weak field strengths $(\sim 100 \mathrm{G})$, called the Zeeman effect, can be categorized under $\sigma$ and $\pi$-polarization. The beam is $\sigma$-polarized if the polarization of the beam is perpendicular to the external magnetic field $(\mathbf{E} \perp \mathbf{B})$. The beam is $\pi$-polarized if the polarization of the beam is parallel to the external magnetic field ( $\mathbf{E} \|$ B). For the Xe II $5 \mathrm{~d}[4]_{7 / 2} \rightarrow 6 \mathrm{p}[3]_{5 / 2}^{0}$ transition, $\pi$-polarized splitting effects are negligible while $\sigma$-polarized splitting effects are not. ${ }^{17}$ By injecting the laser beam with radial polarization to match the approximately radial magnetic field around the Hall thruster exit plane (i.e. $\pi$-polarized injection), we can obtain LIF scans with negligible Zeeman splitting.

Lastly, saturation broadening can also be an issue if the laser intensity is too high. Physically, saturation occurs when the upper state population is sizable compared to the lower state population so that the rate of laser-induced excitation no longer scales linearly with the laser intensity. For the purpose of extracting VDFs, saturation broadening must be avoided because there is no simple way to remove this effect in post-processing. More details on the theoretical basis for saturation broadening can be found in Eckbreth. ${ }^{18}$ A saturation study performed prior to testing showed that saturation broadening is negligible at the laser intensity used in this experiment.

Deconvolution is a mathematical process by which broadening effects can be removed. Due to the lack of knowledge regarding the hyperfine structure constants for the transition used, past LIF experiments have either used the most probable velocity to characterize the results ${ }^{19}$ or did not deconvolve the hyperfine structure out of the result and accepted higher uncertainty. ${ }^{20}$ In a previous study, we experimentally obtained a slightly Doppler-broadened hyperfine structure lineshape via intermodulated optogalvanic spectroscopy. This lineshape is used as the basis for deconvolution, thereby bypassing the need to know the hyperfine structure constants. The methodology and validity for this approach is discussed in a previous paper. ${ }^{14}$

\section{Experimental Setup}

\section{A. Facility}

Experiments were performed in the Large Vacuum Test Facility (LVTF) of the Plasmadynamics and Electric Propulsion Laboratory (PEPL) at the University of Michigan. The LVTF is a $\varphi 6 \mathrm{~m} \times 9 \mathrm{~m}$ stainless steel-clad iron cylindrical chamber. The thruster plume is allowed to expand un-impeded until termination at a carbon beam dump $\sim 4 \mathrm{~m}$ downstream. Pumping is provided by seven cryopumps with a nominal xenon pumping speed of $245,000 \mathrm{l} / \mathrm{s}$. Facility pressure is monitored by two hot-cathode ionization gauges. The base pressure is approximately $4 \times 10^{-7}$ Torr. The pressure during thruster operation at $30 \mathrm{mg} / \mathrm{s}$ anode mass flow rate, the highest of this study, is approximately $1.5 \times 10^{-5}$ Torr, corrected for xenon. ${ }^{21}$

During the experiments, the 6-kW Hall thruster was mounted on two cross-mounted stepper-motor translation stages. The stages provide $1 \mathrm{~m}$ of axial travel and $2 \mathrm{~m}$ of radial travel accurate to within $0.1 \mathrm{~mm}$. Laser injection and LIF collection optics were fixed to the floor of the chamber.

Research-grade xenon propellant $(99.999 \%$ pure) was supplied to the thruster by commercially available flow meters and controllers, having an accuracy of $\pm 1 \%$. Calibration of the flow system was done by the constant volume method taking into account the effects of compressibility.

\section{B. Thruster}

The 6-kW annular Hall thruster ${ }^{13,22-24}$ nominally operates at 300 $\mathrm{V}$ discharge voltage and $20 \mathrm{mg} / \mathrm{s}$ anode mass flow rate. Table 1 lists the operating conditions tested during this experiment. Note that the discharge voltage and anode mass flow rate are the main varying parameters between conditions. For the rest of this paper, operating conditions are labeled as YYY V, ZZ mg/s, where YYY is the discharge voltage and $\mathrm{ZZ}$ is the anode mass flow rate. Cathode mass flow rate is fixed to $7 \%$ of the anode mass flow rate for all operating conditions. Magnetic field settings are chosen to create roughly symmetric magnetic fields about the thruster channel centerline and to maximize thruster efficiency. These settings were

Table 1. List of operating conditions

\begin{tabular}{|c|c|c|}
\hline $\begin{array}{l}\text { Discharge } \\
\text { voltage, } \mathbf{V}\end{array}$ & $\begin{array}{l}\text { Anode mass } \\
\text { flow rate, } \mathbf{m g} / \mathbf{s}\end{array}$ & $\begin{array}{l}\text { Discharge } \\
\text { current, } \text { A }\end{array}$ \\
\hline 150 & 10 & 9.08 \\
\hline 150 & 20 & 21.55 \\
\hline 150 & 30 & 35.35 \\
\hline 300 & 10 & 8.94 \\
\hline 300 & 20 & 20.11 \\
\hline 300 & 30 & 33.25 \\
\hline 600 & 10 & 9.36 \\
\hline
\end{tabular}
found through the use of an inverse pendulum thrust stand. 


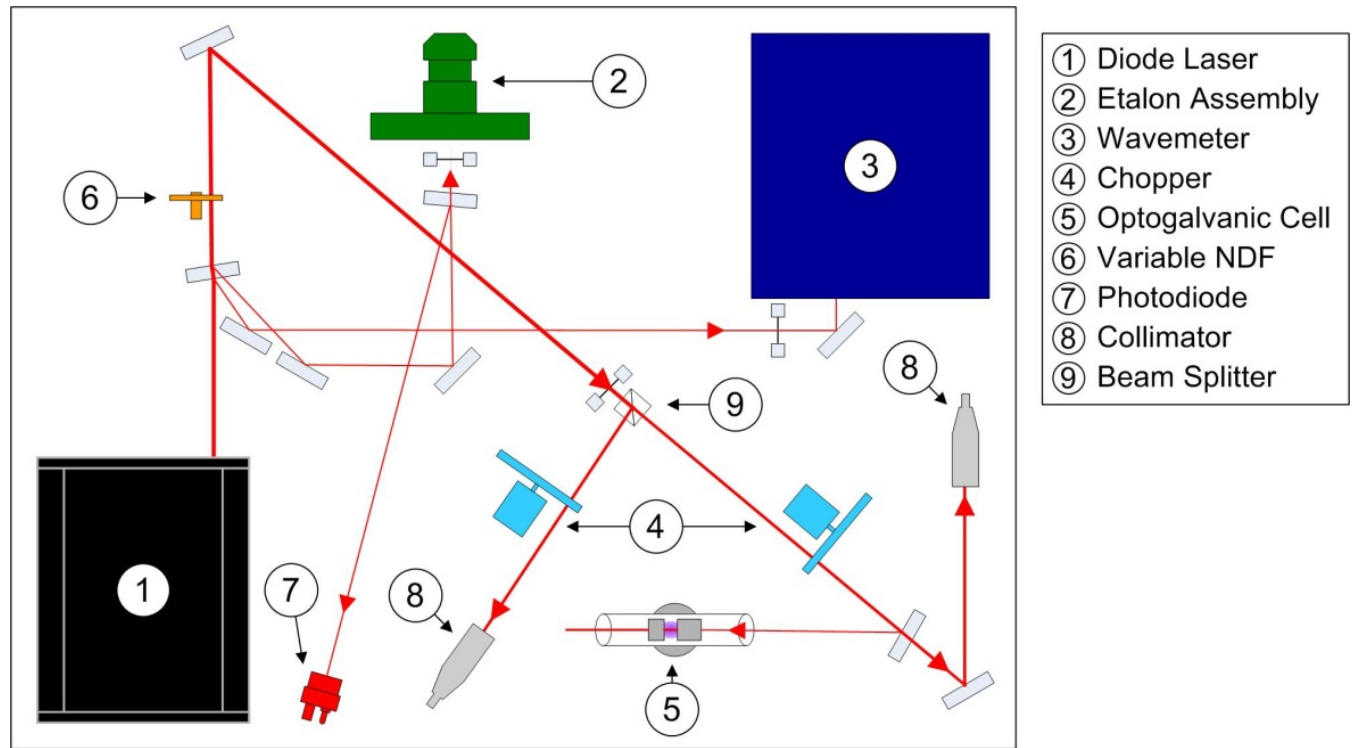

Figure 2. Air-side optical setup.

\section{Air-Side Laser and Injection Optics}

Figure 2 shows the air-side laser and optics setup for the LIF experiment. The laser system used is a TOPTICA TA-100/830 tapered-amplifier diode laser. This system has a nominal linewidth of $\sim 10 \mathrm{MHz}$, a mode-hop-free range of $\sim 12 \mathrm{GHz}$, and a maximum output power of $\sim 250 \mathrm{~mW}$ at $834.953 \mathrm{~nm}$ (vacuum).

For reference information, a Burleigh SA-91 etalon assembly (2-GHz free spectral range, finesse $>300$ ), a Burleigh WA-1000 wavemeter (accurate to $1 \mathrm{pm}$ ), and a Hamamatsu L2783-42 XeNe-Mo optogalvanic cell are used. The optogalvanic cell is made of two cylindrical Mo tube electrodes centered in a glass cylinder filled with approximately 3 Torr of xenon and 4 Torr of neon. The cell is operated at $250 \mathrm{~V}$. The voltage drop across the cell's ballast resistor is connected to an SR-810 lock-in amplifier through an RC high-pass filter.

Additionally, a Thorlabs DET-110 photodiode is used to monitor laser power drift. This reading is fed into another SR-810 lock-in amplifier for signal collection. For unsaturated LIF traces, this laser power reading is used to remove the effects of laser power drift in post-processing. When doing a saturation study, an additional variable neutral density filter is added so that the laser power being injected into the chamber can be controlled.

The main laser beam is split roughly $50: 50$ by a non-polarizing beam splitter cube. The transmitting beam is chopped by a SR540 mechanical chopper at $\sim 1150 \mathrm{~Hz}$ before being collimated into the axial injection fiber. The reflected beam is chopped by another SR540 chopper at $\sim 1660 \mathrm{~Hz}$ before being collimated into the near-radial injection fiber.

During the experiments, all scans were taken with a lock-in amplifier time constant of $100 \mathrm{~ms}$ and a total scan duration of $160 \mathrm{~s}$. Amplifier settings and PMT bias voltage are fixed throughout for each experiment to ensure data are taken under comparable conditions. Laser beam power delivered to the interrogation volume was measured via a thermopile to be $20 \pm 1 \mathrm{~mW}$ giving an average beam intensity of $\sim 2.5 \mathrm{~W} / \mathrm{cm}^{2}$.

\section{Vacuum-Side Optics}

Figure 3 shows a diagram of the vacuum-side optical and thruster setup. Figure 3 a shows how the two sets of injection optics are aligned with respect to the thruster for probing near the inner channel wall. Shown in dash outline is the position of the near-radial injection optics when probing near the outer channel wall. The axial injection optics sends laser light axially into the thruster. The near-radial injection optics is so named because it sends in laser light at a 60 degree angle with respect to the thruster axis, as opposed to radial injection at 90 degrees. Although analysis will be more complicated with a near-radial scheme, it is necessary for the laser light to reach to inside of the thruster channel. The beams are focused down to a point with a 1-mm diameter circular cross section via anti-reflect-coated plano-convex lenses. The injection beam focusing cones have half-angles of $\sim 0.5^{\circ}$ and the injection axes are aligned to within $0.1^{\circ}$ using laser tools so cosine errors are negligible. The interrogation zone is at the 9 o'clock position when viewing the thruster face on. To prevent excess beam drift during thruster operation a shield optic is installed to allow the laser through while protecting the axial optics from xenon particles. 


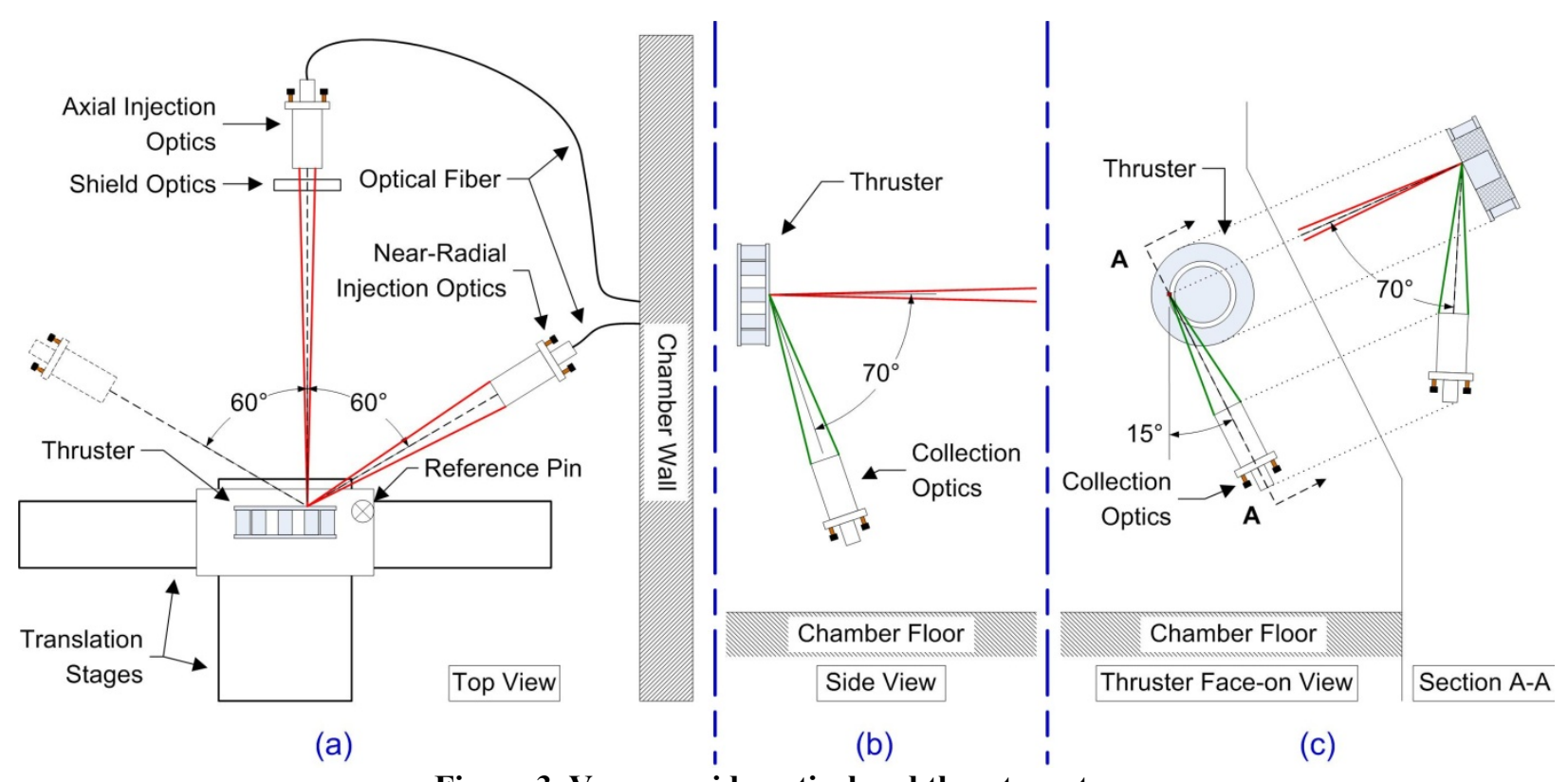

Figure 3. Vacuum-side optical and thruster setup.

Polarizers (not shown in the diagram) are placed between the optical fiber outputs and the lenses to control the beam polarization with respect to the local magnetic field direction. Note that a photon's polarization direction is always perpendicular to the photon's travel direction. For this reason, the polarization of the axial beam can be tuned to match the local magnetic field direction in order to minimize the Zeeman effect, but it is not possible to do the same for the near-radial beam. Instead, we opt to make the polarization of the near-radial beam perpendicular to the local magnetic field in order to excite pure $\sigma$-polarized splitting. The amount of broadening introduced by the Zeeman effect and a possible method for removing any broadening of the near-radial VDF in post processing is discussed in the results section.

Figures $3 \mathrm{~b}$ and $3 \mathrm{c}$ show the two collection optics positions used to collect data from near the inner and outer channel walls, respectively. The axial injection beam is shown for reference. The collection optics are built from a matching pair of anti-reflect-coated achromatic lenses. Thermal shielding is not necessary for these optics based on thermocouple measurements taken prior to testing. Nevertheless, some thermal drift takes place over the course of the test so a reference pin with a 1-mm-diameter hemispherical head is installed to the left of the thruster when viewed face on. The exact position of the head of this pin relative to the thruster is known and the reflected laser signal from this pin is used to compensate for thermal drift. The collection optics axis is set at a $70 \pm 0.5$ degree angle with respect to the thruster axis to allow the interrogation of the inside of the thruster channel. The interrogation volume resulting from the intersection of the injection and collection optics is a sphere of $\sim 1.5 \mathrm{~mm}$ in diameter. The size of this interrogation volume sets the spatial resolution of the LIF measurements.

\section{E. Air-Side Collection Optics}

An optical fiber brings the fluorescence signal from the chamber to a SPEX-500M monochromator, the output of which is amplified by a Hamamatsu R928 photomultiplier. The amplified signal is sent to a SR850 lock-in amplifier and a SR810 lock-in amplifier; the former locks onto the chopping frequency of the axial injection beam while the latter locks onto the chopping frequency of the near-radial injection beam. The monochromator slit size is $1 \mathrm{~mm}$, which corresponds to an optical bandwidth of $\sim 1 \mathrm{~nm}$. Based on information from the NIST Atomic Spectra Database, the wavelength range formed by a bandwidth of $1 \mathrm{~nm}$ around the $541.9 \mathrm{~nm}$ (air) transition includes one other xenon ion line and two other xenon neutral lines. The $541.9 \mathrm{~nm}$ (air) transition is listed on the database as at least two orders of magnitude stronger than these three other lines so we can be reasonably assured that most of the signal (and noise) comes only from the target transition. 


\section{Data Reduction}

For this experiment, signal-to-noise ratio (SNR) is defined as the peak intensity of the trace divided by the root-mean-square value of the noise fluctuations. The SNR of a trace is considered too low if it is $<10$ because at this point the noise contribute significantly to the uncertainty of the velocity measurements.

Deconvolution of the hyperfine structure lineshapes from the raw LIF data was carried out using Fourier transform with an inverse Gaussian filter. ${ }^{25}$ Uncertainty in the bulk velocity (mean velocity) shown in this paper is primarily limited by the laser linewidth and secondarily by the SNR. For a 95\%-confidence-interval, the uncertainty in the velocity measurement is $\pm 50 \mathrm{~m} / \mathrm{s}$. Furthermore, the equipment used to generate the stationary reference is estimated to have an error of $\sim 2 \%$. Thus, unless otherwise specified, the uncertainty in the bulk velocity measurements is $\pm 50 \mathrm{~m} / \mathrm{s}$ or $\pm 2 \%$, whichever is greater. Note that since SNR varies greatly across operating conditions and locations in the Hall thruster, there are some LIF scans with greater uncertainties. The uncertainties in these data are reported separately as is appropriate. Also note that the $2 \%$

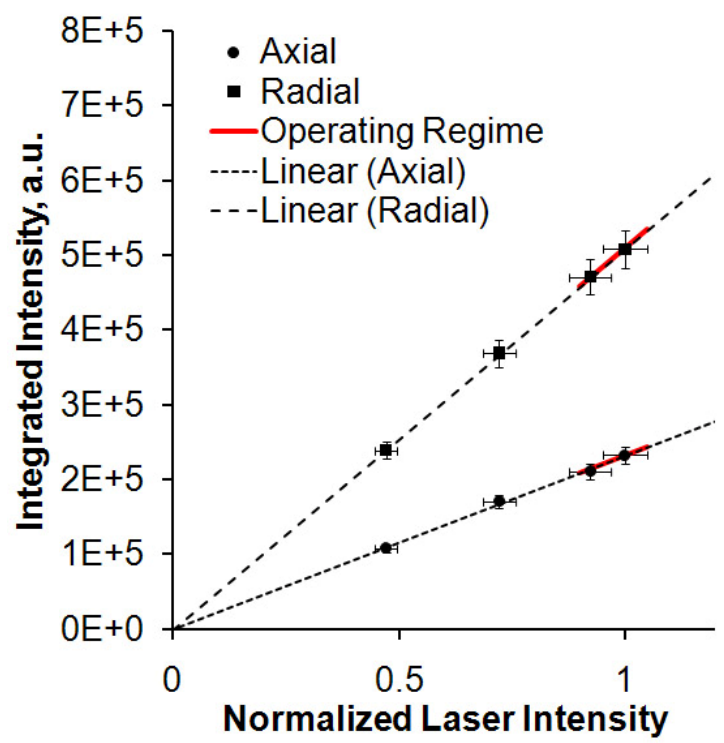

Figure 4. Saturation study for the experiment. error in the stationary reference is empirically determined through prior LIF and optogalvanic experiments with similar setups using the same transition. The primary source of this error is believed to be thermal drift in the equipment. The same inverse Gaussian filter that removes most of the noise also broadens the VDF. Care is taken to make sure this broadening is less than $5 \%$ unless otherwise specified. The nature of the deconvolution method is such that this broadening does not affect the calculated bulk velocity.

The average angle of incidence is calculated from two bulk velocity measurements at each location. For 95\%confidence across all data locations the uncertainty in angle is no greater than $\pm 3^{\circ}$, as calculated using the uncertainties of the associated bulk velocities.

Figure 4 shows the saturation study plot for the experiment. The effect of saturation is shown to be negligible for both the axial and the radial beams as indicated by the linear response of the fluorescence intensity to the input laser intensity.

\section{Results}

\section{A. Velocity Vector Plots}

All radial coordinates are normalized by the nominal discharge channel width where $\mathrm{R}=0$ at the inner channel wall and $\mathrm{R}=1$ at the outer channel wall. All axial coordinates are normalized by the discharge channel length where $\mathrm{Z}=0$ at the channel exit plane and $\mathrm{Z}=-1$ at the anode exit plane.

Figure 5 shows the original data location matrix at the start of the test as well as the erosion pattern measured by a contact coordinate-measuring-machine (CMM). The CMM measurement is sufficiently accurate that the spatial coordinate error is less than the width of the line. The CMM measurements were taken right before the LIF test, at which time the thruster had accumulated $\sim 330$ hours of operation. Of those operating hours, $\sim 30 \%$ were operated on $300 \mathrm{~V}, 10 \mathrm{mg} / \mathrm{s}, \sim 30 \%$ on $300 \mathrm{~V}, 20 \mathrm{mg} / \mathrm{s}, \sim 10 \%$ on $300 \mathrm{~V}, 30 \mathrm{mg} / \mathrm{s}$, and $6-8 \%$ each on the remaining four operating conditions listed in Table 1. Actual data shown in this paper are filtered by the criterion that the SNR must be roughly 10 or greater. Any data locations that appear to be blank in the results plots have traces with insufficient SNR. 


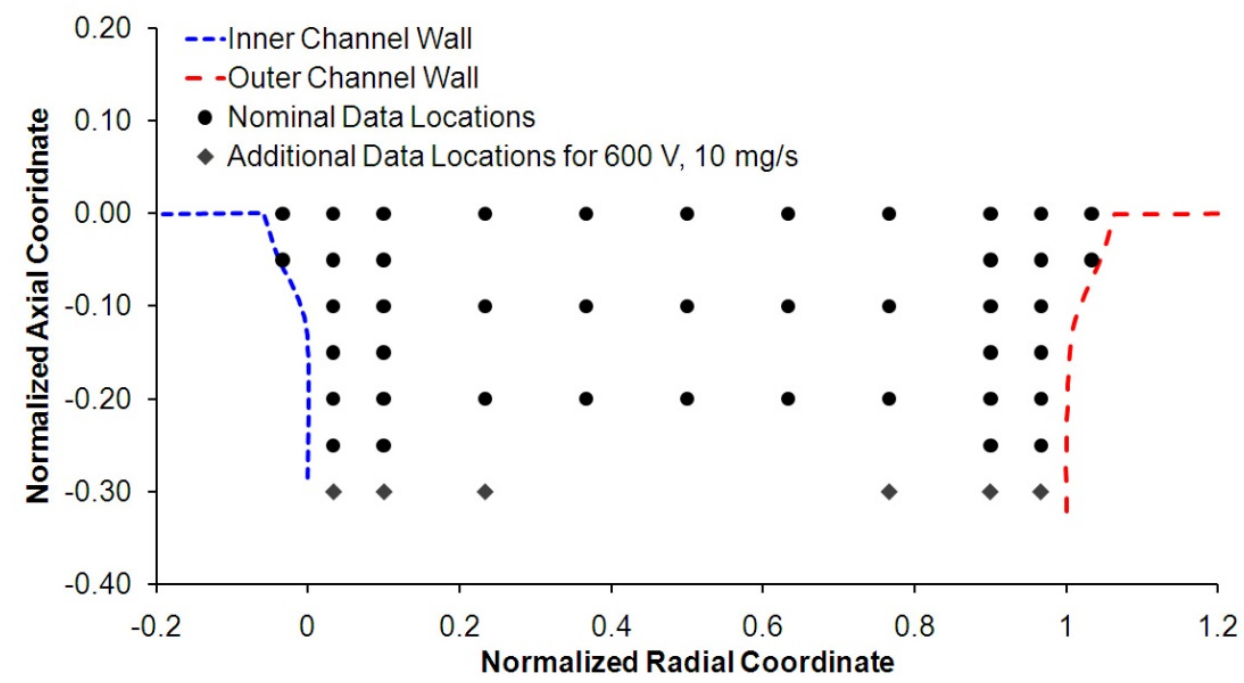

Figure 5. Data location matrix and discharge channel wall profiles. Blue short-dashed line shows the inner channel wall profile obtained from a coordinate-measuring-machine. Red long-dashed line shows the outer channel wall profile. The $600 \mathrm{~V}, 10 \mathrm{mg} / \mathrm{s}$ condition contains additional data locations because its acceleration zone extends further upstream than other conditions.

Figure 6 shows the ion velocity vector plot for $300 \mathrm{~V}, 10 \mathrm{mg} / \mathrm{s}$ operation. Velocity vector plots for the other six operating conditions are shown in the Appendix as Figs. 12-17. From Fig. 6, we can see that the mean speeds of the ions are very low until they reach the acceleration zone near the exit plane. The velocity vectors are generally very focused near the center of the channel but diverge near the two channel walls. The near-wall velocity vectors appear to be pointed into the wall at all measured axial locations.

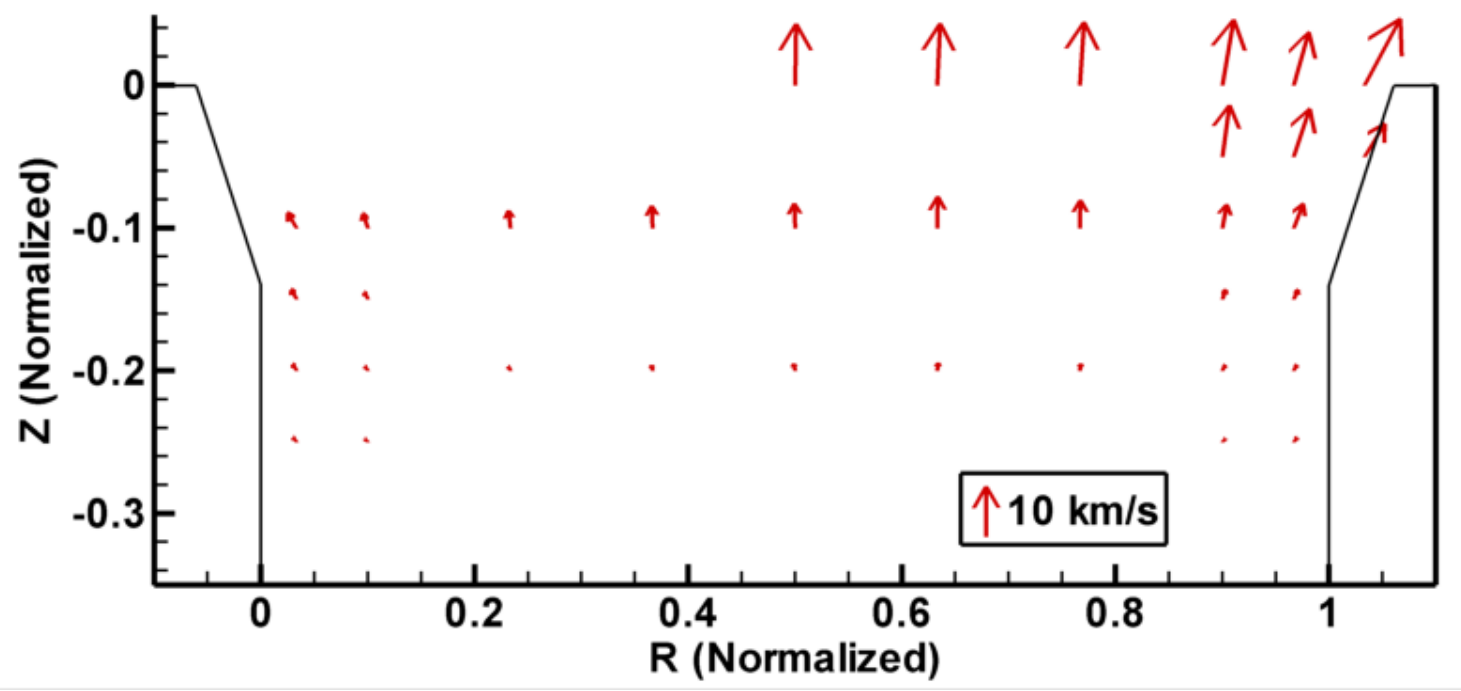

Figure 6. Ion velocity vector plot for $300 \mathrm{~V}, 10 \mathrm{mg} / \mathrm{s}$ operation.

A reference vector is included to show the length of a $10 \mathrm{~km} / \mathrm{s}$ vector. 
Table 2. Summary of ion speed, energy, and angle near the channel walls for $300 \mathrm{~V}, 10 \mathrm{mg} / \mathrm{s}$ operation.

\begin{tabular}{|l|r|c|r|r|r|r|r|r|r|r|}
\hline & \multicolumn{4}{|c|}{ Inner Wall } & \multicolumn{5}{|c|}{ Outer Wall } \\
\hline $\mathbf{Z}$ & $\mathbf{R}$ & $\begin{array}{l}\text { Mean } \\
\text { speed, } \\
\mathbf{m} / \mathbf{s}\end{array}$ & $\begin{array}{l}\text { Equivalent } \\
\text { energy, eV }\end{array}$ & $\begin{array}{l}\text { Mean } \\
\text { angle, } \\
\mathbf{d e g}\end{array}$ & $\begin{array}{l}\text { Angle } \\
\text { w/rt wall, } \\
\text { deg }\end{array}$ & $\mathbf{R}$ & $\begin{array}{l}\text { Mean } \\
\text { speed, } \\
\text { m/s }\end{array}$ & $\begin{array}{l}\text { Equivalent } \\
\text { energy, eV }\end{array}$ & $\begin{array}{l}\text { Mean } \\
\text { angle, } \\
\text { deg }\end{array}$ & $\begin{array}{l}\text { Angle } \\
\text { w/rt wall, } \\
\text { deg }\end{array}$ \\
\hline $\mathbf{0 . 0 0}$ & $\mathbf{- 0 . 0 3}$ & - & - & - & - & $\mathbf{1 . 0 3}$ & 16337 & 181.6 & 35.7 & 15.7 \\
\hline $\mathbf{- 0 . 0 5}$ & $\mathbf{- 0 . 0 3}$ & - & - & - & - & $\mathbf{1 . 0 3}$ & 8452 & 48.6 & 39.4 & 20.2 \\
\hline $\mathbf{- 0 . 1 0}$ & $\mathbf{0 . 0 3}$ & 3937 & 10.5 & -38.3 & -21.4 & $\mathbf{0 . 9 7}$ & 5470 & 20.4 & 27.4 & 7.8 \\
\hline $\mathbf{- 0 . 1 5}$ & $\mathbf{0 . 0 3}$ & 2481 & 4.2 & -35.3 & -33.3 & $\mathbf{0 . 9 7}$ & 2195 & 3.3 & 31.3 & 26.3 \\
\hline $\mathbf{- 0 . 2 0}$ & $\mathbf{0 . 0 3}$ & 1654 & 1.9 & -35.9 & -36.6 & $\mathbf{0 . 9 7}$ & 1382 & 1.3 & 34.3 & 32.7 \\
\hline $\mathbf{- 0 . 2 5}$ & $\mathbf{0 . 0 3}$ & 1340 & 1.2 & -45.3 & -45.3 & $\mathbf{0 . 9 7}$ & 1209 & 1.0 & 46.6 & 46.6 \\
\hline
\end{tabular}

Table 2 contains detailed information regarding the speed, equivalent energy, and angle of the ion population found near the wall at each axial location for $300 \mathrm{~V}, 10 \mathrm{mg} / \mathrm{s}$ operation. The near-wall data summaries for the other six operating conditions are shown in Tables 3-8. For $\mathrm{Z}=-0.05$ and 0 , the data in these tables come from $\mathrm{R}=-0.03$ and 1.03 . For $Z=-0.3$ to -0.1 , the data in these tables come from $R=0.03$ and 0.97 . If the SNR is too low at the location so designated, the entry is marked with "-.". Note that the true mean energy of the ions can only be calculated by constructing the angular energy distribution function and then averaging. For the purpose of these seven data summary tables, the equivalent kinetic energy based on the mean speed is calculated instead. Mean angles are measured with respect to the firing axis of the thruster where positive angles indicate radially outward flow and negative angles indicate radially inward flow. The ion angle with respect to the wall is calculated by subtracting the angle of the wall from the ion angle at the same axial location. From Tables 2-8, we see that deep inside the channel, upstream of the acceleration zone, the ions are pointed at the wall but have little energy (less than a few tens of eV). This is consistent with the picture of a slowly drifting plasma undergoing ambipolar diffusion to the channel walls. The axial drift of these ions is likely inherited from the drift of the neutrals before being ionized. As the ions travel downstream they begin to accelerate, gaining energy. The mean angle with respect to the firing axis for the near-wall ions seems to become smaller suggesting that they are becoming more focused but not by much (10-15 degrees reduction out of 30-45 degrees). The near-wall ions remain fairly de-focused at all axial locations. When we take the angles of the walls into account we see an interesting trend where at $Z=-0.10$ the ion angle with respect to wall is much smaller than everywhere else. A quick look at Fig. 5 shows that $Z=-0.10$ corresponds to furthest upstream position where the channel wall erosion is clearly discernable.

To study this trend more carefully, we now plot the mean angle of incidence as a function of axial position for the two operating conditions that have data with the highest SNR. This plot, Fig. 7, shows the angle of incidence (AOI) as a function of axial position for operation at $150 \mathrm{~V}, 10 \mathrm{mg} / \mathrm{s}$ and $300 \mathrm{~V}, 10 \mathrm{mg} / \mathrm{s}$. The AOI is the incoming

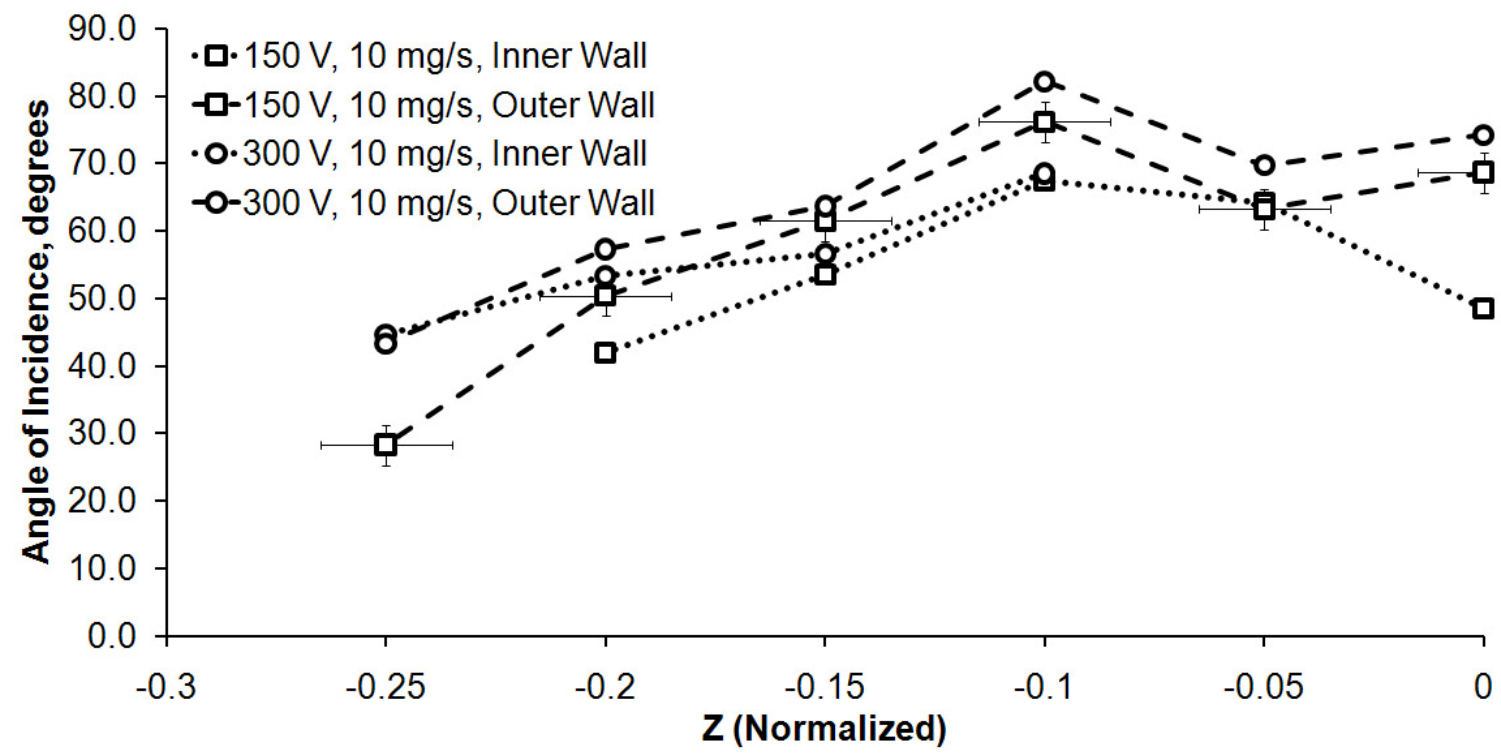

Figure 7. Angle of incidence at the channel walls as a function of normalized axial coordinate for operation at $150 \mathrm{~V}, 10 \mathrm{mg} / \mathrm{s}$ and $300 \mathrm{~V}, 10 \mathrm{mg} / \mathrm{s}$. One set of representative error bars is plotted. 
angle of the bombarding particles with respect to the wall normal, and can be calculated by subtracting the absolute value of the angle with respect to the wall from 90 degrees. An AOI of 0 degrees means the bombarding particles are approaching the wall perpendicular to the surface plane, while an AOI of 90 degrees means the bombarding particles flow parallel to the wall. From Fig. 5, we see that erosion takes place mostly between $\mathrm{Z}=-0.10$ and $\mathrm{Z}=0$. Existing sputter theories tell us that erosion rate is highest at 60-70 degrees $\mathrm{AOI}^{2}$ and quickly falls to 0 as $\mathrm{AOI}$ approaches 90 , when particle velocity becomes parallel to the wall. It is interesting to see that of all the eroded axial locations, $\mathrm{Z}=-0.1$ is the closest to 90 for both 150 and $300 \mathrm{~V}$ operation on both channel walls. Other operating conditions for which there is sufficient data show similar trends. One possible explanation is that although the ion flow near the wall is always divergent, the ions do not pick up enough energy to erode the wall significantly until $\mathrm{Z}$ of roughly -0.10 . Past this point, the erosion rate increases due to rapidly increasing bombardment energy as shown in Tables 2-8. It is possible that the furthest upstream point in the erosion zone $(Z=-0.10)$ is closest to reaching its terminal erosion profile, for which the nearby flow is nearly parallel with the wall. Meanwhile, the locations closer to the exit plane $(Z=-0.05$ and 0$)$ are still undergoing a large amount of erosion as the channel evolves toward its terminal erosion profile. In this paper, the phrase "terminal erosion profile" refers to the erosion profile at the end of the life of a Hall thruster. Accounting for the ion density and sheath potential variation will complicate the picture but the overall trend should hold. Further investigation combining LIF and wall probe data taken by Shastry ${ }^{26}$ will yield great insight on this phenomenon.

\section{B. Axial Velocity Distribution Functions}

Although the mean speed gives us some information about the average bombardment energy of the ions, it does not give a complete picture as ions with much higher energy than the average can exist. Erosion theories generally predict some energy threshold below which negligible erosion occurs. Yim's dissertation contains a good summary of existing models. ${ }^{27}$ Though the specific values vary, the threshold energy is generally in the range of tens of eV. However, Tables 2-8 and Fig. 5 show many axial locations for where the equivalent energy is much less than the threshold energy and yet clear signs of channel erosion still appear. It is likely that the high-energy tail of the energy distribution function exceeds the threshold energy at these locations and is responsible for at least part of the observed erosion. As will be explained later, we are not yet ready to extract angular energy distribution functions from the LIF data. Instead, we will plot the axial VDFs in this paper since the ion velocities before they reach the sheath are primarily in the axial direction.

Figures 8 and 9 show the axial ion VDF along the inner and outer channel walls, respectively, for $300 \mathrm{~V}, 10$ $\mathrm{mg} / \mathrm{s}$ operation. A pair of vertical dashed lines in the figures indicates the axial velocities that correspond to equivalent threshold energies of 25 and $50 \mathrm{eV}$. Although the actual energy will require knowledge of the radial VDF as well, these dashed lines roughly indicate how much of the ion population has energy greater than the threshold values. The values of 25 and $50 \mathrm{eV}$ are chosen to be representative of typically energy threshold values and are not from any specific model. As the figures show, axial locations showing discernable erosion $(Z=-0.10$ to $Z=0)$ also correspond to VDFs with measurable high energy populations. Axial VDFs for other operating conditions show similar trends.

Note that Figs. 8 and 9 also show large amounts of VDF broadening in the downstream locations. For example, at $Z=-0.10$, the mean speed of the ions near the walls is only $4-5.5 \mathrm{~km} / \mathrm{s}$, corresponding to $10-20 \mathrm{eV}$, but the FWHM velocity in the axial VDF is $\sim 6 \mathrm{~km} / \mathrm{s}$, indicating a very large spread in particle energy. There is also bimodal behavior in some of the scans from data locations corresponding to the erosion zone. One possible explanation for these trends is that the breathing mode is causing the entire acceleration zone to oscillate back and forth in the axial direction. At a fixed location within this oscillating zone the ion velocity can vary greatly as a function time. Since this LIF study is time-averaged, the resulting VDFs would show large spread. More details on how the breathing mode can give rise to a bi-modal time-averaged VDF can be found in a previous work. ${ }^{13}$ If the breathing mode oscillation is indeed broadening the ion VDF, the resulting high energy ions may play a very important role in determining both the location and the rate of erosion in the Hall thruster. 


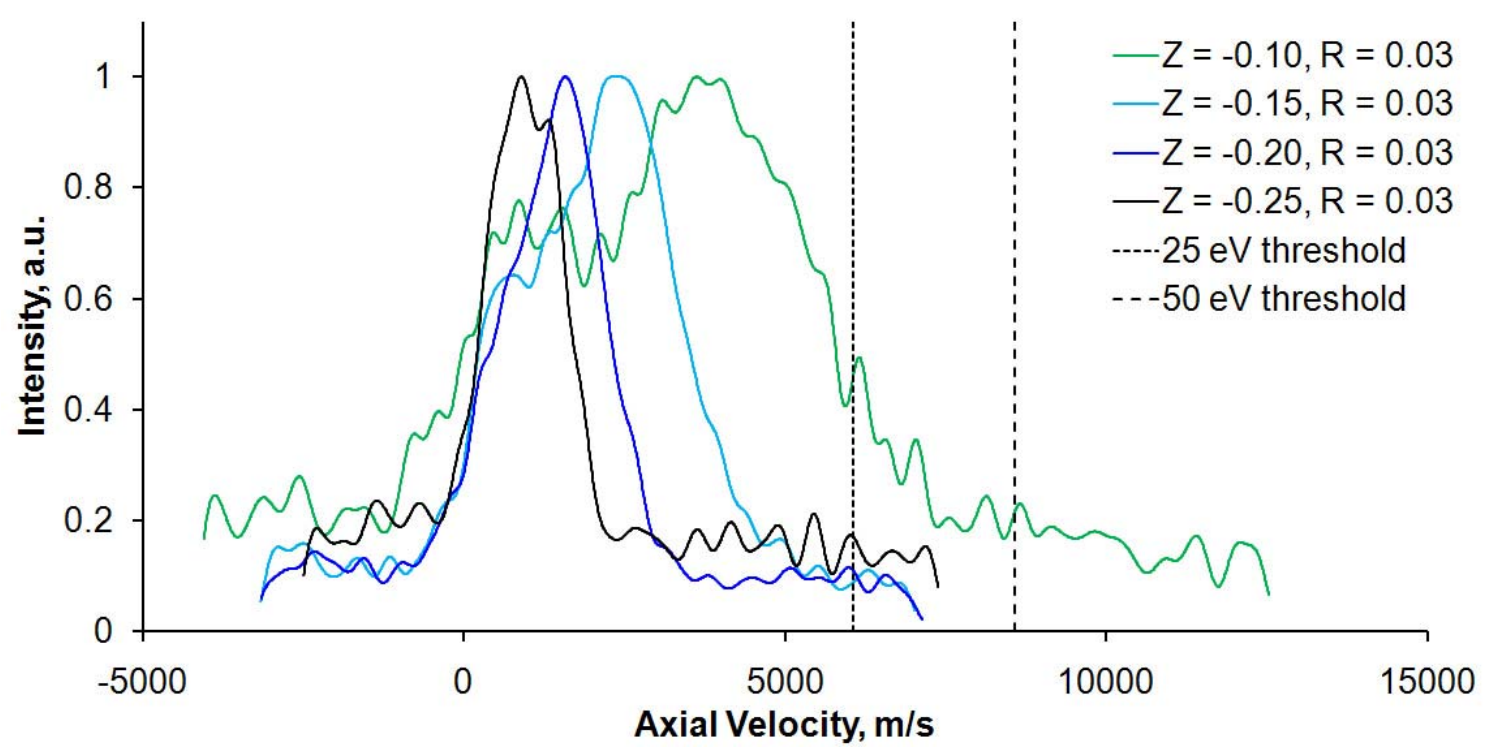

Figure 8. Evolution of axial ion VDF along the inner channel wall for $300 \mathrm{~V}, 10 \mathrm{mg} / \mathrm{s}$ operation.

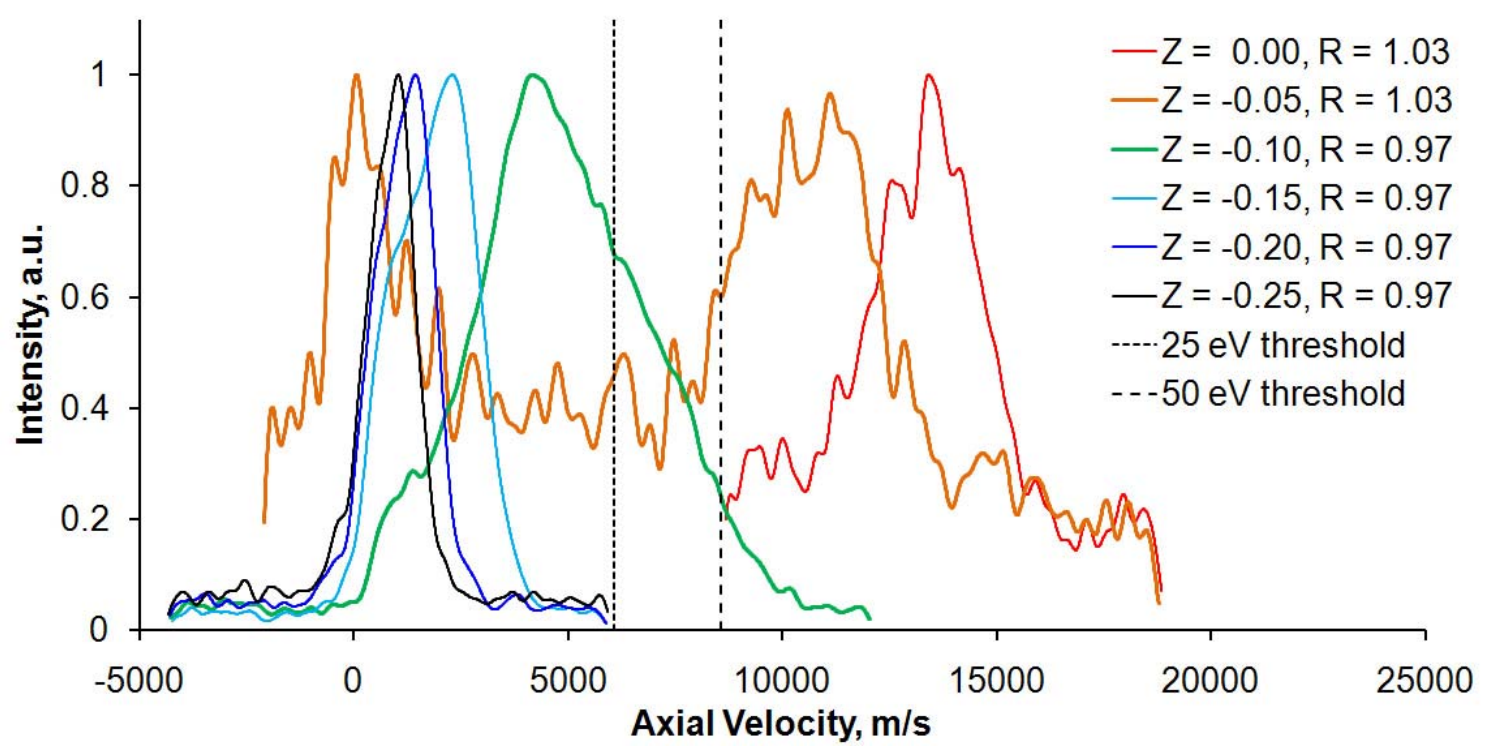

Figure 9. Evolution of axial ion VDF along the outer channel wall for $300 \mathrm{~V}, 10 \mathrm{mg} / \mathrm{s}$ operation. 


\section{Radial Velocity Distribution Functions and Possible Treatment}

As stated in the experimental setup section, it is not possible to align the polarization of the near-radial beam to be parallel with the magnetic field direction at the data locations of this test. Instead, the polarization was set to be perpendicular with respect to the local magnetic field line in order to excite pure $\sigma$-polarized Zeeman splitting. In order to recover the actual radial VDF, we will need to remove the broadening due to the Zeeman effect. Note that the Zeeman effect only broadens the distribution and does not change the value of the mean velocity.

From a previous study of the Zeeman Effect on another xenon line, ${ }^{28}$ we expect the amount of Zeeman effect broadening of the Xe II $5 \mathrm{~d}[4]_{7 / 2} \rightarrow 6 \mathrm{p}[3]^{\circ}{ }_{5 / 2}$ transition to be small relative to the width of the VDF found in the acceleration zone. However, the amount of broadening may become important for the VDF found deep inside the channel, upstream of the acceleration zone. Figures 10 and 11 show examples of near-radial ion VDF along the inner and outer channel walls, respectively, for $300 \mathrm{~V}, 10 \mathrm{mg} / \mathrm{s}$ operation. The upstream traces $(\mathrm{Z}=-0.25$ to -0.10$)$ in Figs. 10 and 11 do not show any obvious signs of Zeeman splitting, from which we can infer that any broadening due to the Zeeman effect is less than the FWHM velocity of these VDFs. Since the downstream traces $(Z=-0.05$ to 0 ) are several times wider than the upstream traces, we can deduce that the Zeeman effect is likely negligible for the

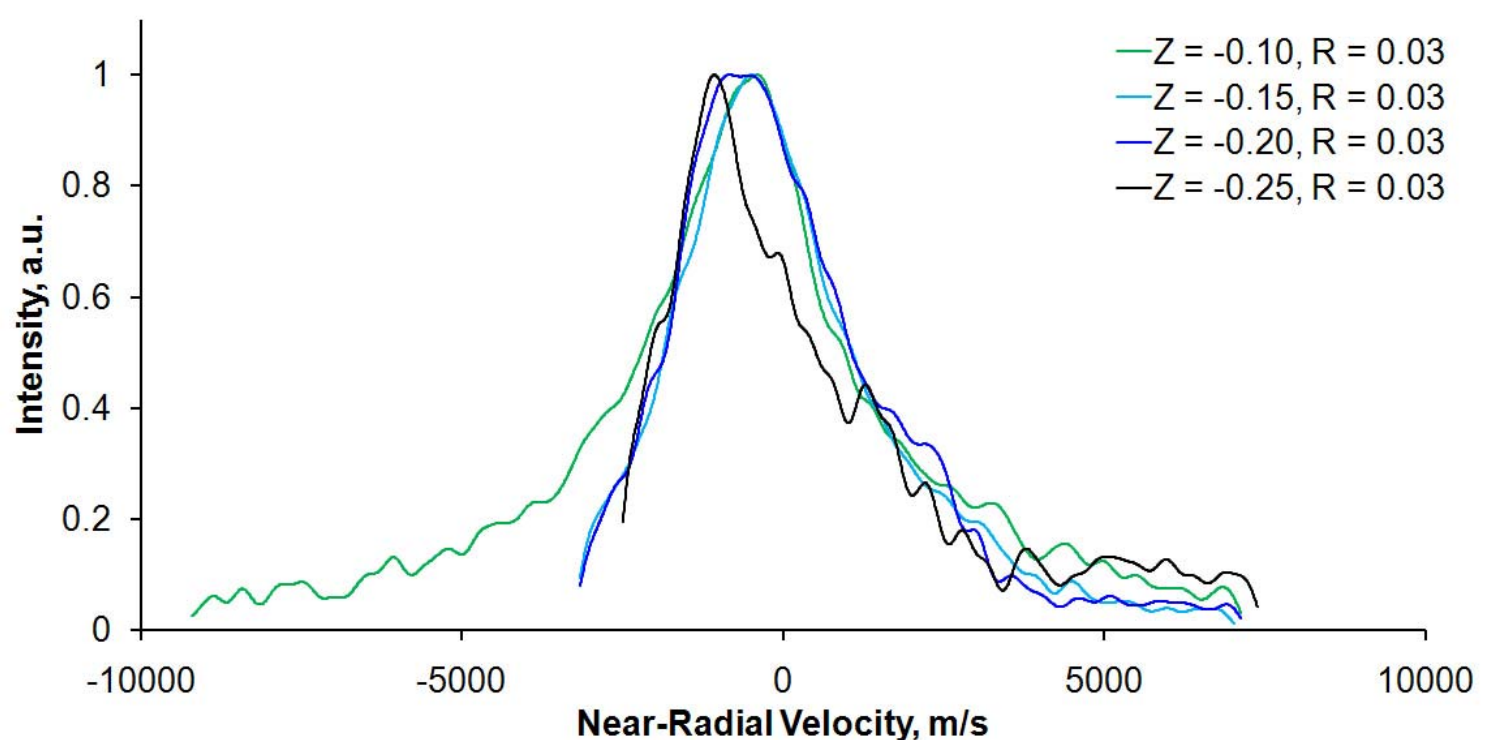

Figure 10. Evolution of near-radial ion VDF along the inner channel wall for $300 \mathrm{~V}, 10 \mathrm{mg} / \mathrm{s}$ operation.

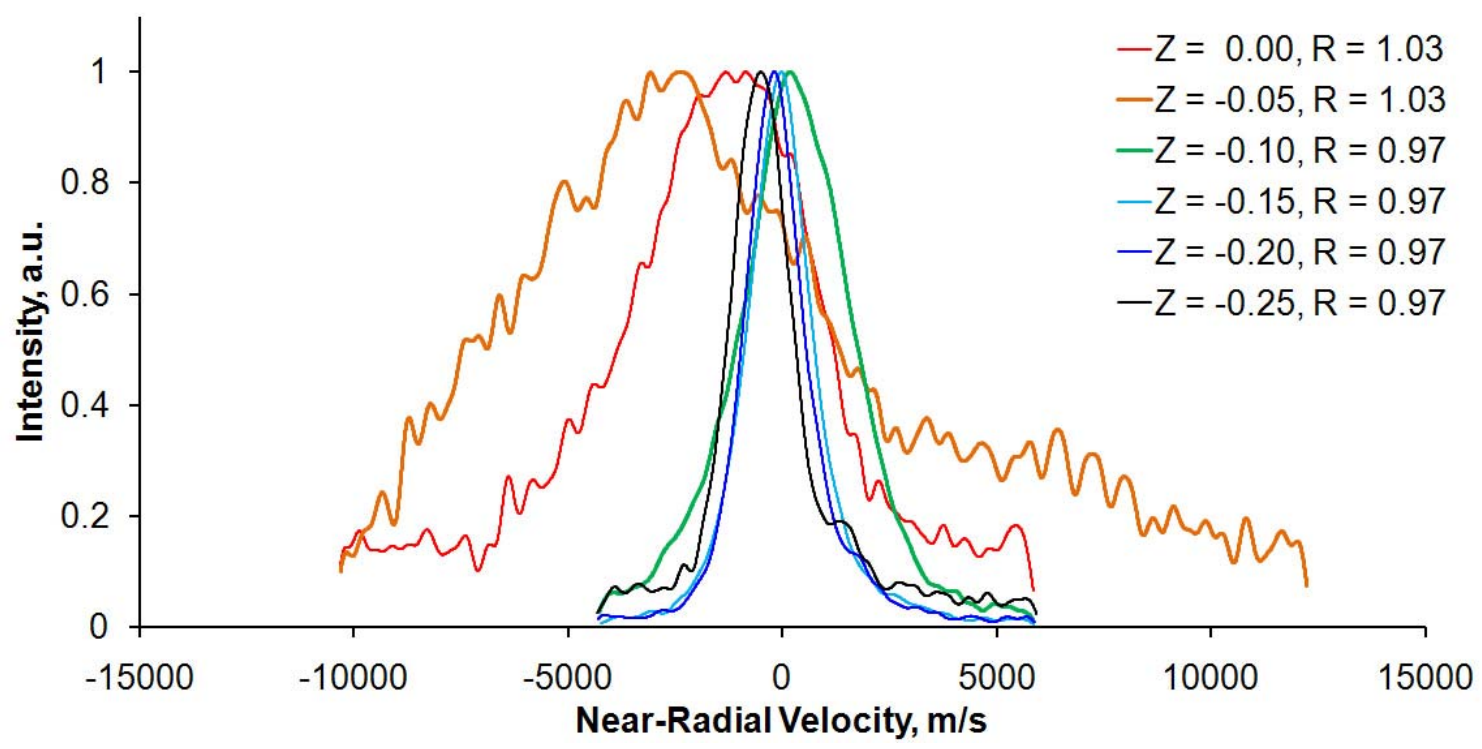

Figure 11. Evolution of near-radial ion VDF along the outer channel wall for $300 \mathrm{~V}, 10 \mathrm{mg} / \mathrm{s} \mathrm{operation}$. 
downstream traces.

To rigorously determine whether the Zeeman effect is really an issue in the near-radial traces and how it can to be accounted for, we propose the following approach for future work. We will begin by performing an experiment very similar to a previous study in which we experimentally measured a hyperfine structure for the purpose of deconvolving it out of our raw data. ${ }^{14}$ The difference between the new proposed experiment and the old one is that we will now immerse the optogalvanic cell containing the xenon ions in a controlled magnetic field environment where the geometry induces pure $\sigma$-polarized Zeeman splitting. We will construct a map of the hyperfine structure lineshapes as a function of magnetic field strength. From another previous study, we know that the in-situ magnetic field strength is generally no greater than 10 Gauss off from the magnetic field strength in air. ${ }^{29}$ In other words, a map of the in-air magnetic field is a good approximation of the in-situ magnetic field. Knowing that all near-radial traces are pure $\sigma$-polarized, we can use the in-air magnetic field and the results of the proposed experiment to predict the Zeeman-split hyperfine structures. At this point, the predicted amount of splitting can be compared to the width of the near-radial VDF to decide whether or not the Zeeman effect needs to be accounted for. Deconvolution can then be used to remove Zeeman effect broadening if necessary. This is left for future work.

\section{Conclusions}

We have described a novel 2-D LIF experiment that has the potential to extract angular energy distribution functions for ions bombarding the discharge channel walls of a 6-kW Hall thruster. The bulk velocity vector plots show that the ions near the channel walls are always pointed toward the walls. However, these ions are generally not energetic enough to cause erosion upstream of the acceleration zone. The axial extent of the acceleration zone appears to overlap the axial extent of the erosion zone. The ion vectors at axial location $Z=-0.10$ (the position furthest upstream in the erosion zone) are closest to being parallel to the walls for all operating conditions, suggesting that this axial location has a profile that is closest to the thruster's terminal erosion profile.

Detailed examination of axial VDFs and the erosion profile shows a strong correlation between axial locations with VDFs that contain high-energy ions (greater than a few tens of eV) and axial locations with eroded channel walls. Furthermore, axial locations upstream of the erosion zone have VDFs with comparatively low-energy ions. These data support the idea of an energy threshold (on the order of a few tens of eV) below which negligible erosion takes place. And that even if the mean energy of the ions is lower than the threshold energy, the high energy tail of the VDF can still cause erosion.

Future work will focus on combining LIF data with wall probe data to paint a more complete picture of the erosion processes taking place in the Hall thruster. Additional future work will focus on the treatment of the nearradial LIF data to remove any Zeeman effect broadening. Lastly, we will attempt to extract angular energy distribution functions of the bombarding ions by combining the two-axis VDF data. 


\section{Appendix}

Figures 12-17 show the ion velocity vector plots for operations at $150 \mathrm{~V}, 10 \mathrm{mg} / \mathrm{s}, 150 \mathrm{~V}, 20 \mathrm{mg} / \mathrm{s}, 150 \mathrm{~V}, 30$ $\mathrm{mg} / \mathrm{s}, 300 \mathrm{~V}, 20 \mathrm{mg} / \mathrm{s}, 300 \mathrm{~V}, 30 \mathrm{mg} / \mathrm{s}$, and $600 \mathrm{~V}, 10 \mathrm{mg} / \mathrm{s}$, respectively.

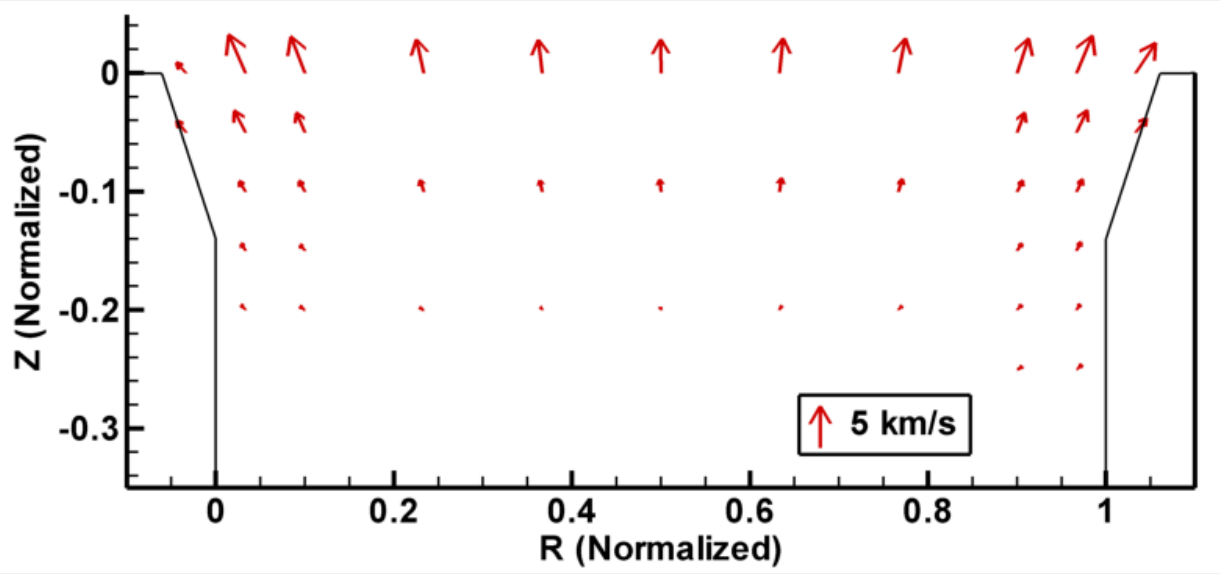

Figure 12. Ion velocity vector plot for $150 \mathrm{~V}, 10 \mathrm{mg} / \mathrm{s}$ operation.

A reference vector is included to show the length of a $5 \mathrm{~km} / \mathrm{s}$ vector.

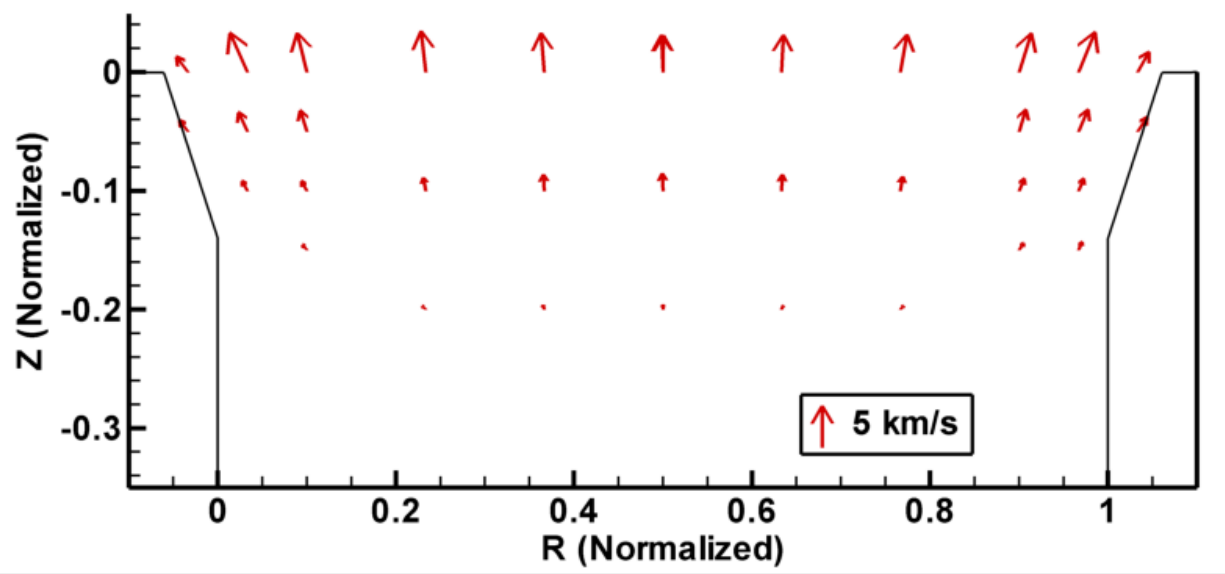

Figure 13. Ion velocity vector plot for $150 \mathrm{~V}, 20 \mathrm{mg} / \mathrm{s}$ operation.

A reference vector is included to show the length of a $5 \mathrm{~km} / \mathrm{s}$ vector.

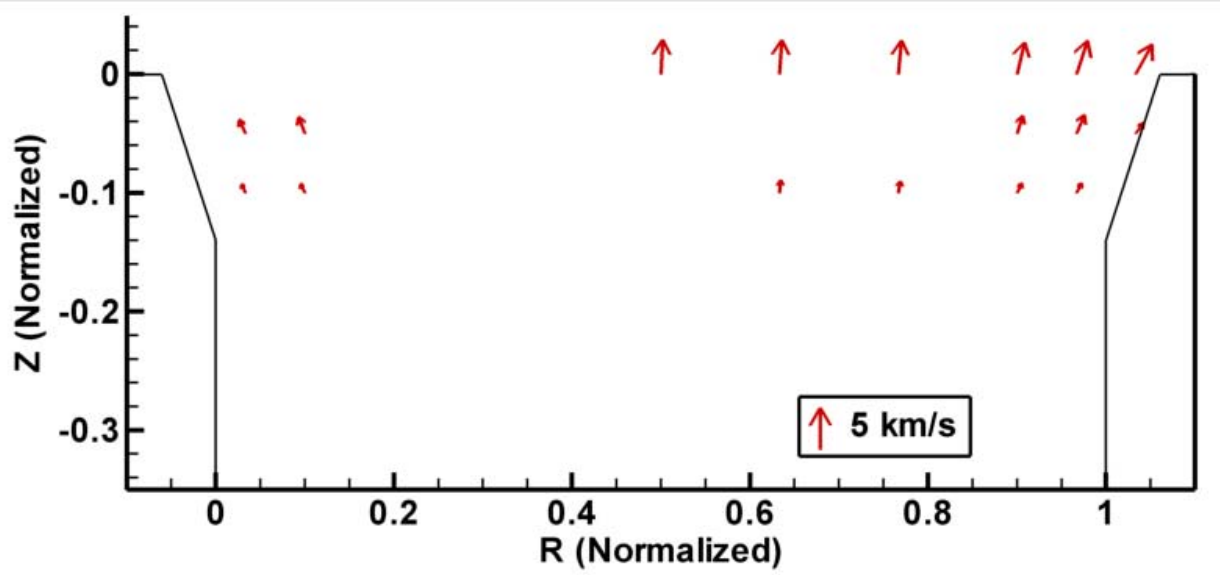

Figure 14. Ion velocity vector plot for $150 \mathrm{~V}, 30 \mathrm{mg} / \mathrm{s}$ operation.

A reference vector is included to show the length of a $5 \mathrm{~km} / \mathrm{s}$ vector. 


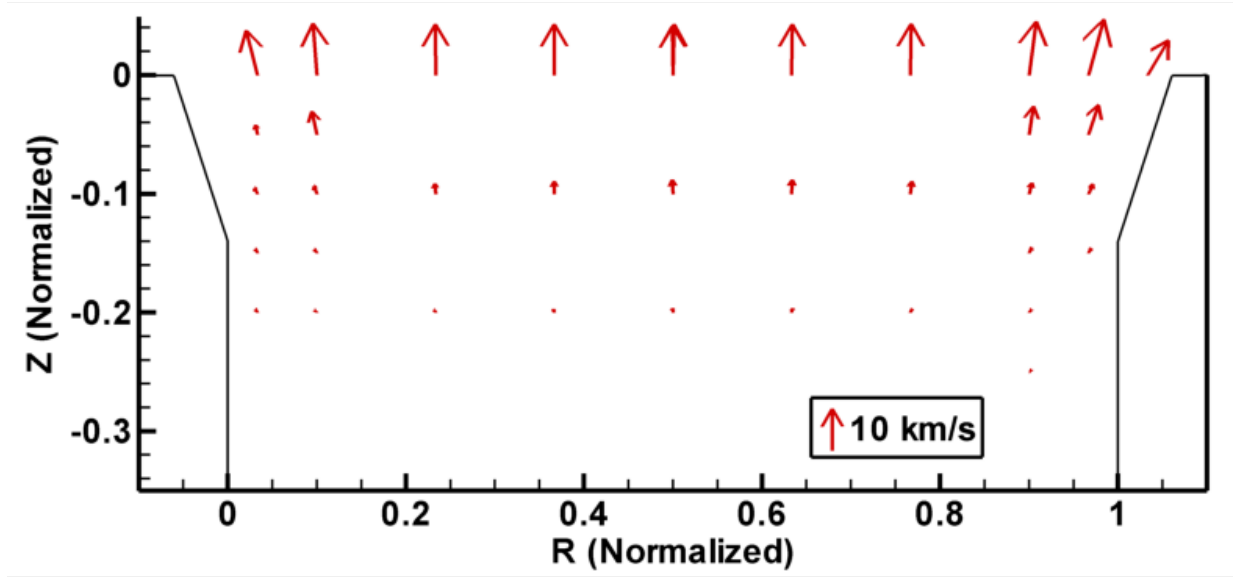

Figure 15. Ion velocity vector plot for $300 \mathrm{~V}, 20 \mathrm{mg} / \mathrm{s}$ operation.

A reference vector is included to show the length of a $10 \mathrm{~km} / \mathrm{s}$ vector.

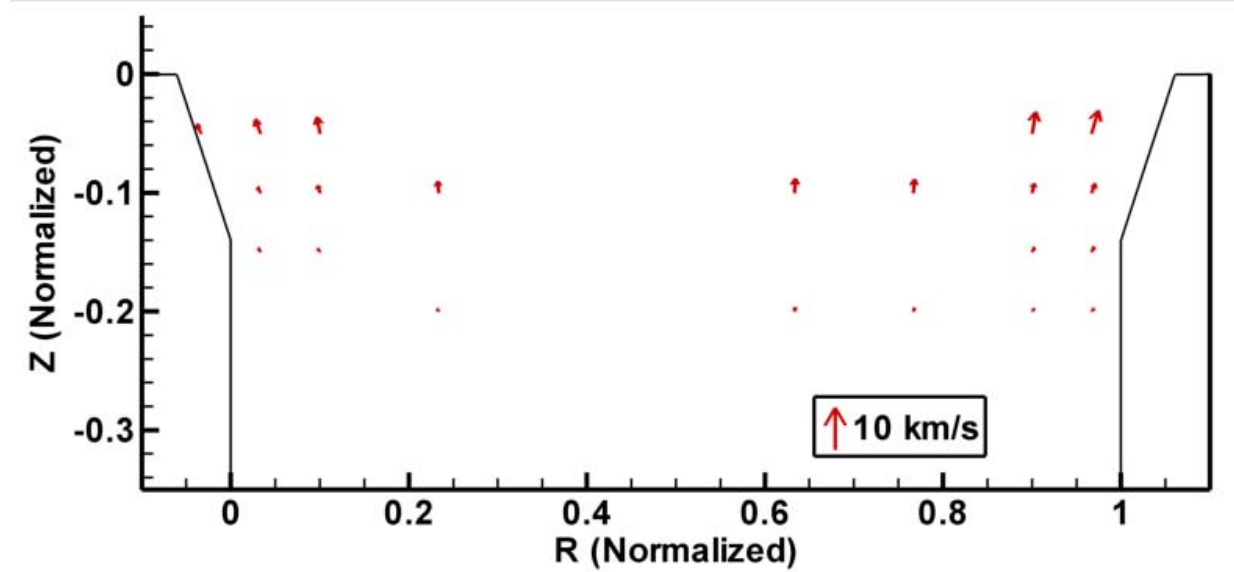

Figure 16. Ion velocity vector plot for $300 \mathrm{~V}, 30 \mathrm{mg} / \mathrm{s}$ operation.

A reference vector is included to show the length of a $10 \mathrm{~km} / \mathrm{s}$ vector.

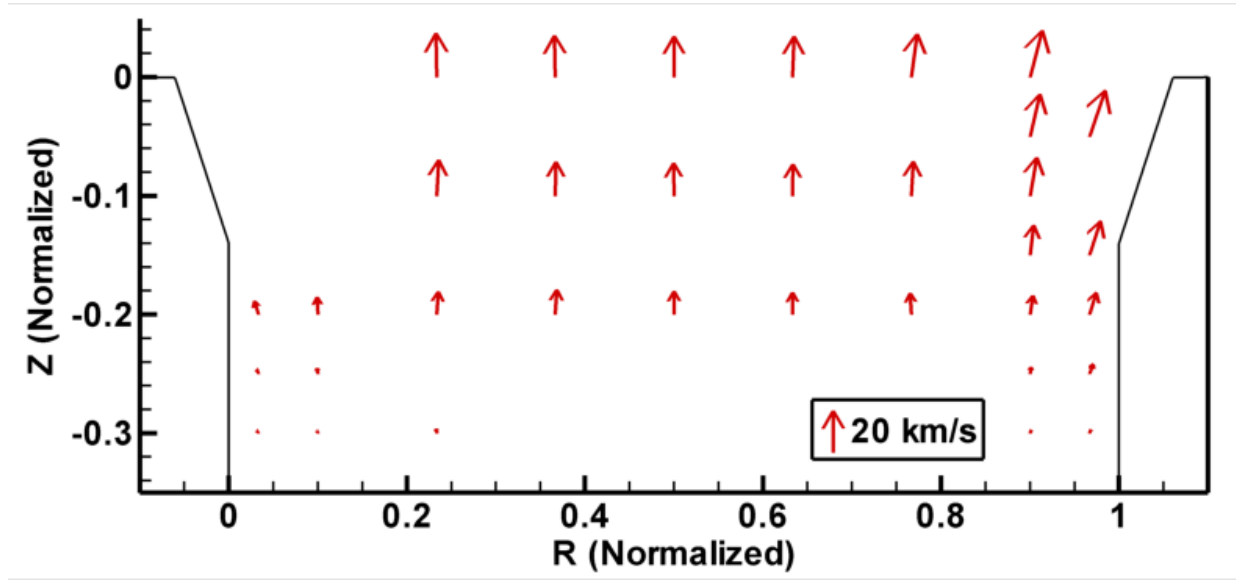

Figure 17. Ion velocity vector plot for $600 \mathrm{~V}, 10 \mathrm{mg} / \mathrm{s}$ operation. A reference vector is included to show the length of a $20 \mathrm{~km} / \mathrm{s}$ vector. 
Tables 3-8 contain detailed information regarding the speed, equivalent energy, and angle of the ion population found near the channel walls for operations at $150 \mathrm{~V}, 10 \mathrm{mg} / \mathrm{s}, 150 \mathrm{~V}, 20 \mathrm{mg} / \mathrm{s}, 150 \mathrm{~V}, 30 \mathrm{mg} / \mathrm{s}, 300 \mathrm{~V}, 20 \mathrm{mg} / \mathrm{s}, 300$ $\mathrm{V}, 30 \mathrm{mg} / \mathrm{s}$, and $600 \mathrm{~V}, 10 \mathrm{mg} / \mathrm{s}$, respectively.

Table 3. Summary of ion speed, energy, and angle near the channel walls for $150 \mathrm{~V}, 10 \mathrm{mg} / \mathrm{s} \mathrm{operation}$.

\begin{tabular}{|l|r|r|r|r|r|r|r|r|r|r|}
\hline & \multicolumn{4}{|c|}{ Inner Wall } & \multicolumn{5}{|c|}{ Outer Wall } \\
\hline $\mathbf{Z}$ & $\mathbf{R}$ & $\begin{array}{l}\text { Mean } \\
\text { speed, } \\
\mathbf{m} / \mathbf{s}\end{array}$ & $\begin{array}{l}\text { Equivalent } \\
\text { energy, eV }\end{array}$ & $\begin{array}{l}\text { Mean } \\
\text { angle, } \\
\text { deg }\end{array}$ & $\begin{array}{l}\text { Angle } \\
\text { w/rt wall, } \\
\text { deg }\end{array}$ & $\mathbf{R}$ & $\begin{array}{l}\text { Mean } \\
\text { speed, } \\
\text { m/s }\end{array}$ & $\begin{array}{l}\text { Equivalent } \\
\text { energy, eV }\end{array}$ & $\begin{array}{l}\text { Mean } \\
\text { angle, } \\
\text { deg }\end{array}$ & $\begin{array}{l}\text { Angle } \\
\text { w/rt wall, } \\
\text { deg }\end{array}$ \\
\hline $\mathbf{0 . 0 0}$ & $\mathbf{- 0 . 0 3}$ & 2010 & 2.7 & -51.6 & -41.4 & $\mathbf{1 . 0 3}$ & 4792 & 15.6 & 41.3 & 21.3 \\
\hline $\mathbf{- 0 . 0 5}$ & $\mathbf{- 0 . 0 3}$ & 2088 & 3.0 & -48.3 & -25.7 & $\mathbf{1 . 0 3}$ & 2431 & 4.0 & 45.9 & 26.7 \\
\hline $\mathbf{- 0 . 1 0}$ & $\mathbf{0 . 0 3}$ & 1638 & 1.8 & -39.5 & -22.6 & $\mathbf{0 . 9 7}$ & 1794 & 2.2 & 33.4 & 13.8 \\
\hline $\mathbf{- 0 . 1 5}$ & $\mathbf{0 . 0 3}$ & 1114 & 0.8 & -38.4 & -36.4 & $\mathbf{0 . 9 7}$ & 1247 & 1.1 & 33.5 & 28.5 \\
\hline $\mathbf{- 0 . 2 0}$ & $\mathbf{0 . 0 3}$ & 922 & 0.6 & -47.3 & -48.0 & $\mathbf{0 . 9 7}$ & 913 & 0.6 & 41.2 & 39.6 \\
\hline $\mathbf{- 0 . 2 5}$ & $\mathbf{0 . 0 3}$ & - & - & - & - & $\mathbf{0 . 9 7}$ & 1038 & 0.7 & 61.7 & 61.7 \\
\hline
\end{tabular}

Table 4. Summary of ion speed, energy, and angle near the channel walls for $150 \mathrm{~V}, 20 \mathrm{mg} / \mathrm{s} \mathrm{operation.}$

\begin{tabular}{|l|r|r|r|r|r|r|r|r|r|r|}
\hline & \multicolumn{4}{|c|}{ Inner Wall } & \multicolumn{5}{|c|}{ Outer Wall } \\
\hline$Z$ & $\mathbf{R}$ & $\begin{array}{l}\text { Mean } \\
\text { speed, } \\
\text { m/s }\end{array}$ & $\begin{array}{l}\text { Equivalent } \\
\text { energy, eV }\end{array}$ & $\begin{array}{l}\text { Mean } \\
\text { angle, } \\
\text { deg }\end{array}$ & $\begin{array}{l}\text { Angle } \\
\text { w/rt wall, } \\
\text { deg }\end{array}$ & $\mathbf{R}$ & $\begin{array}{l}\text { Mean } \\
\text { speed, } \\
\text { m/s }\end{array}$ & $\begin{array}{l}\text { Equivalent } \\
\text { energy, eV }\end{array}$ & $\begin{array}{l}\text { Mean } \\
\text { angle, } \\
\text { deg }\end{array}$ & $\begin{array}{l}\text { Angle } \\
\text { w/rt wall, } \\
\text { deg }\end{array}$ \\
\hline $\mathbf{0 . 0 0}$ & $\mathbf{- 0 . 0 3}$ & 2682 & 4.9 & -45.6 & -35.4 & $\mathbf{1 . 0 3}$ & 3009 & 6.2 & 36.0 & 16.0 \\
\hline $\mathbf{- 0 . 0 5}$ & $\mathbf{- 0 . 0 3}$ & 1956 & 2.6 & -47.1 & -24.5 & $\mathbf{1 . 0 3}$ & 2295 & 3.6 & 40.7 & 21.5 \\
\hline $\mathbf{- 0 . 1 0}$ & $\mathbf{0 . 0 3}$ & 1499 & 1.5 & -36.0 & -19.1 & $\mathbf{0 . 9 7}$ & 1712 & 2.0 & 29.8 & 10.2 \\
\hline $\mathbf{- 0 . 1 5}$ & $\mathbf{0 . 0 3}$ & 1146 & 0.9 & -36.1 & -34.1 & $\mathbf{0 . 9 7}$ & 1151 & 0.9 & 29.3 & 24.3 \\
\hline $\mathbf{- 0 . 2 0}$ & $\mathbf{0 . 0 3}$ & - & - & - & - & $\mathbf{0 . 9 7}$ & 488 & 0.2 & 26.0 & 24.4 \\
\hline
\end{tabular}

Table 5. Summary of ion speed, energy, and angle near the channel walls for $150 \mathrm{~V}, 30 \mathrm{mg} / \mathrm{s}$ operation.

\begin{tabular}{|c|c|c|c|c|c|c|c|c|c|c|}
\hline & \multicolumn{5}{|c|}{ Inner Wall } & \multicolumn{5}{|c|}{ Outer Wall } \\
\hline $\mathbf{Z}$ & $\mathbf{R}$ & $\begin{array}{l}\text { Mean } \\
\text { speed, } \\
\text { m/s }\end{array}$ & $\begin{array}{l}\text { Equivalent } \\
\text { energy, eV }\end{array}$ & $\begin{array}{l}\text { Mean } \\
\text { angle, } \\
\text { deg }\end{array}$ & $\begin{array}{l}\text { Angle } \\
\text { w/rt wall, } \\
\text { deg }\end{array}$ & $\mathbf{R}$ & $\begin{array}{l}\text { Mean } \\
\text { speed, } \\
\text { m/s }\end{array}$ & $\begin{array}{l}\text { Equivalent } \\
\text { energy, eV }\end{array}$ & $\begin{array}{l}\text { Mean } \\
\text { angle, } \\
\text { deg }\end{array}$ & $\begin{array}{l}\text { Angle } \\
\text { w/rt wall, } \\
\text { deg }\end{array}$ \\
\hline 0.00 & -0.03 & - & - & - & - & 1.03 & 4446 & 13.4 & 36.3 & 16.3 \\
\hline-0.05 & -0.03 & - & - & - & - & 1.03 & 1732 & 2.0 & 44.5 & 25.3 \\
\hline-0.10 & 0.03 & 1243 & 1.1 & -31.9 & -15.0 & 0.97 & 1418 & 1.4 & 35.3 & 15.7 \\
\hline
\end{tabular}

Table 6. Summary of ion speed, energy, and angle near the channel walls for $300 \mathrm{~V}, 20 \mathrm{mg} / \mathrm{s}$ operation.

\begin{tabular}{|c|c|c|c|c|c|c|c|c|c|c|}
\hline & \multicolumn{5}{|c|}{ Inner Wall } & \multicolumn{5}{|c|}{ Outer Wall } \\
\hline $\mathbf{Z}$ & $\mathbf{R}$ & $\begin{array}{l}\text { Mean } \\
\text { speed, } \\
\mathbf{m} / \mathbf{s}\end{array}$ & $\begin{array}{l}\text { Equivalent } \\
\text { energy, eV }\end{array}$ & $\begin{array}{l}\text { Mean } \\
\text { angle, } \\
\text { deg }\end{array}$ & $\begin{array}{l}\text { Angle } \\
\text { w/rt wall, } \\
\text { deg }\end{array}$ & $\mathbf{R}$ & $\begin{array}{l}\text { Mean } \\
\text { speed, } \\
\mathbf{m} / \mathbf{s}\end{array}$ & $\begin{array}{l}\text { Equivalent } \\
\text { energy, eV }\end{array}$ & $\begin{array}{l}\text { Mean } \\
\text { angle, } \\
\text { deg }\end{array}$ & $\begin{array}{l}\text { Angle } \\
\text { w/rt wall, } \\
\text { deg }\end{array}$ \\
\hline $\mathbf{0}$ & -0.03 & - & - & - & - & 1.03 & 10674 & 77.5 & 38 & 18 \\
\hline-0.05 & -0.03 & - & - & - & - & 1.03 & - & - & - & - \\
\hline-0.1 & 0.03 & 1724 & 2 & -33.4 & -16.5 & 0.97 & 2674 & 4.9 & 31.2 & 11.6 \\
\hline-0.15 & 0.03 & 1263 & 1.1 & -31.8 & -29.8 & 0.97 & 1426 & 1.4 & 32.8 & 27.8 \\
\hline-0.2 & 0.03 & 997 & 0.7 & -37.8 & -38.5 & 0.97 & 953 & 0.6 & 36 & 34.4 \\
\hline
\end{tabular}


Table 7. Summary of ion speed, energy, and angle near the channel walls for $300 \mathrm{~V}, 30 \mathrm{mg} / \mathrm{s}$ operation.

\begin{tabular}{|c|c|c|c|c|c|c|c|c|c|c|}
\hline & \multicolumn{5}{|c|}{ Inner Wall } & \multicolumn{5}{|c|}{ Outer Wall } \\
\hline $\mathbf{Z}$ & $\mathbf{R}$ & $\begin{array}{l}\text { Mean } \\
\text { speed, } \\
\mathbf{m} / \mathbf{s} \\
\end{array}$ & $\begin{array}{l}\text { Equivalent } \\
\text { energy, eV }\end{array}$ & $\begin{array}{l}\text { Mean } \\
\text { angle, } \\
\text { deg }\end{array}$ & $\begin{array}{l}\text { Angle } \\
\text { w/rt wall, } \\
\text { deg }\end{array}$ & $\mathbf{R}$ & $\begin{array}{l}\text { Mean } \\
\text { speed, } \\
\text { m/s }\end{array}$ & $\begin{array}{l}\text { Equivalent } \\
\text { energy, eV }\end{array}$ & $\begin{array}{l}\text { Mean } \\
\text { angle, } \\
\text { deg }\end{array}$ & $\begin{array}{l}\text { Angle } \\
\text { w/rt wall, } \\
\text { deg }\end{array}$ \\
\hline-0.05 & -0.03 & 2644 & 4.8 & -31.8 & -9.2 & 1.03 & - & - & - & - \\
\hline-0.10 & 0.03 & 1648 & 1.8 & -31.1 & -14.2 & 0.97 & 2487 & 4.2 & 28.5 & 8.9 \\
\hline-0.15 & 0.03 & 1153 & 0.9 & -36.3 & -34.3 & 0.97 & 1455 & 1.4 & 34.0 & 29.0 \\
\hline-0.20 & 0.03 & - & - & - & - & 0.97 & 1026 & 0.7 & 48.3 & 46.7 \\
\hline
\end{tabular}

Table 8. Summary of ion speed, energy, and angle near the channel walls for $600 \mathrm{~V}, 10 \mathrm{mg} / \mathrm{s}$ operation.

\begin{tabular}{|c|c|c|c|c|c|c|c|c|c|c|}
\hline & \multicolumn{5}{|c|}{ Inner Wall } & \multicolumn{5}{|c|}{ Outer Wall } \\
\hline $\mathbf{Z}$ & $\mathbf{R}$ & $\begin{array}{l}\text { Mean } \\
\text { speed, } \\
\text { m/s }\end{array}$ & $\begin{array}{l}\text { Equivalent } \\
\text { energy, eV }\end{array}$ & $\begin{array}{l}\text { Mean } \\
\text { angle, } \\
\text { deg }\end{array}$ & $\begin{array}{l}\text { Angle } \\
\text { w/rt wall, } \\
\text { deg }\end{array}$ & $\mathbf{R}$ & $\begin{array}{l}\text { Mean } \\
\text { speed, } \\
\text { m/s }\end{array}$ & $\begin{array}{l}\text { Equivalent } \\
\text { energy, eV }\end{array}$ & $\begin{array}{l}\text { Mean } \\
\text { angle, } \\
\text { deg }\end{array}$ & $\begin{array}{l}\text { Angle } \\
\text { w/rt wall, } \\
\text { deg }\end{array}$ \\
\hline-0.20 & 0.03 & - & - & - & - & 0.97 & 11505 & 90.1 & 22.4 & 20.8 \\
\hline-0.25 & 0.03 & 2376 & 3.8 & -24.6 & -24.6 & 0.97 & 5294 & 19.1 & 25.7 & 25.7 \\
\hline-0.30 & 0.03 & 1634 & 1.8 & -36.9 & -36.9 & 0.97 & 1995 & 2.7 & 29.5 & 29.5 \\
\hline
\end{tabular}

\section{Acknowledgments}

The authors would like to acknowledge and thank the Air Force Office of Scientific Research (AFOSR) for funding this research. Dr. Mitat Birkan is the Project Manager for Grant FA9550-06-1-0105.

\section{References}

${ }^{1}$ Manzella, D., Yim, J., and Boyd, I., "Predicting Hall Thruster Operational Lifetime", 40th AIAA/ASME/SAE/ASEE Joint Propulsion Conference \& Exhibit, AIAA-2004-3953, Fort Lauderdale, FL, 11-14 Jul., 2004.

${ }^{2}$ Yim, J. T., Keidar, M., and Boyd, I. D., "An Investigation of Factors Involved in Hall Thruster Wall Erosion Modeling", 42nd AIAA/ASME/SAE/ASEE Joint Propulsion Conference \& Exhibit, AIAA-2006-4657, Sacramento, CA, 9-12 Jul., 2006.

${ }^{3}$ Hofer, R. R., Mikellides, I. G., Katz, I., and Goebel, D. M., "BPT-4000 Hall Thruster Discharge Chamber Erosion Model Comparison with Qualification Life Test Data", 30th International Electric Propulsion Conference, 2007-267, Florence, Italy, 17-20 Sep., 2007.

${ }^{4}$ Sommier, E., Scharfe, M. K., Gascon, N., Capelli, M. A., and Fernandez, E., "Simulating Plasma-Induced Hall Thruster Wall Erosion With a Two-Dimensional Hybrid Model", IEEE Transactions on Plasma Science, Vol. 35, No. 5, doi:10.1109/TPS.2007.905943, Oct., 2007, pp. 1379-1387.

${ }^{5}$ Garnier, Y., Viel, V., Roussel, J. F., and Bernard, J., "Low-energy xenon ion sputtering of ceramics investigated for stationary plasma thrusters", Journal of Vacuum Science and Technology, Vol. 17, No. 6, doi:10.1116/1.582050, Nov/Dec, 1999, pp. 32463254 .

${ }^{6}$ Yamamura, Y., "Theory of Sputtering and Comparison to Experimental Data", Nuclear Instruments and Methods, Vol. 194, No. 1-3, doi:10.1016/0029-554X(82)90575-4, Nov., 1982, pp. 515-522.

${ }^{7}$ Zhang, Z. L. and Zhang, L., "Anisotropic Angular Distribution of Sputtered Atoms", Radiation Effects \& Defects in Solids, Vol. 159, No. 5, doi:10.1080/10420150410001724495, May, 2004, pp. 301-307.

${ }^{8}$ Rubin, B., Topper, J. L., and Yalin, A. P., "Total and Differential Sputter Yields of Boron Nitride Measured by Quartz Crystal Microbalance", 31st International Electric Propulsion Conference, 2009-042, Ann Arbor, MI, 20-24 Sep., 2009.

${ }^{9}$ Hargus, W. A., Jr. and Nakles, M. R., "Ion Velocity Measurements within the Acceleration Channel of a Lower Power Hall Thruster", 30th International Electric Propulsion Conference, 2007-172, Florence, Italy, 17-20 Sep., 2007.

${ }^{10}$ Nakles, M. R. and William A. Hargus, J., "Background Pressure Effects on Internal and Near-field Ion Velocity Distribution of the BHT-600 Hall Thruster", 44th AIAA/ASME/SAE/ASEE Joint Propulsion Conference \& Exhibit, AIAA-2008-5101, Hartford, CT, 21-23 Jul., 2008.

${ }^{11}$ Hargus, W. A., Jr., Nakles, M. R., Tedrake, R., and Pote, B., "Effect of Anode Current Fluctuations on Ion Energy Distributions within a $600 \mathrm{~W}$ Hall Effect Thruster", 44th AIAA/ASME/SAE/ASEE Joint Propulsion Conference \& Exhibit, AIAA-2008-4724, Hartford, CT, 21-23 Jul., 2008.

${ }^{12}$ Hargus, W. A., Jr. and Cappelli, M. A., "Laser-induced fluorescence measurements of velocity within a Hall discharge", Applied Physics B, Vol. 72, No. 8, doi:10.1007/s003400100589, Jun., 2001, pp. 961-969.

${ }^{13}$ Huang, W., Drenkow, B., and Gallimore, A. D., "Laser-Induced Fluorescence of Singly-Charged Xenon Inside a 6-kW Hall Thruster", 45th AIAA/ASME/SAE/ASEE Joint Propulsion Conference \& Exhibit, AIAA-2009-5355, Denver, CO, $2-5$ Aug., 2009. 
${ }^{14}$ Huang, W., Smith, T. B., and Gallimore, A. D., "Obtaining Velocity Distribution using a Xenon Ion Line with Unknown Hyperfine Constants", 40th AIAA Plasmadynamics and Laser Conference, AIAA-2009-4226, San Antonio, Texas, 22-25 Jun., 2009.

${ }^{15}$ Svanberg, S., Atomic and Molecular Spectroscopy, $4^{\text {th }}$ ed., Springer-Verlag, Berlin, 2004.

${ }^{16}$ Harkness, H. W. and Heard, J. F., "The Stark Effect for Xenon", Proceedings of the Royal Society of London. Series A, Containing Papers of a Mathematical and Physical Character, Vol. 139, No. 838, doi:10.1098/rspa.1933.0027, Feb., 1933, pp. 416-435.

${ }^{17}$ Smith, T. B., Huang, W., Ngom, B. B., and Gallimore, A. D., "Optogalvanic and Laser-induced Fluorescence Spectroscopy of the Zeeman Effect in Xenon", 30th International Electric Propulsion Conference, 2007-229, Florence, Italy, 17-20 Sep., 2007.

${ }^{18}$ Eckbreth, A. C., Saturation Approach to Quenching, in Laser Diagnostics for Combustion Temperature and Species, Ch. 7 , Prentice-Hall, Englewood Cliffs, N.J., 1996, pp. 403-413.

${ }^{19}$ Hargus, W. A., Jr. and Charles, C. S., "Near Exit Plane Velocity Field of a 200-Watt Hall Thruster", Journal of Propulsion and Power, Vol. 24, No. 1, doi:10.2514/1.29949, Jan.-Feb., 2008, pp. 127-133.

${ }^{20}$ Gawron, D., Mazouffre, S., Sadeghi, N., and Heron, A., "Influence of Magnetic Field and Discharge Voltage on the Acceleration Layer Features in a Hall Effect Thruster", Plasma Sources Science and Technology, Vol. 17, No. 2, doi:10.1088/0963-0252/17/2/025001, May, 2008, pp. 025001.

${ }^{21}$ Dushman, S., Scientific Foundations of Vacuum Technique, 1st ed., Ch. 4, Wiley, New York, 1958.

${ }^{22}$ Reid, B. M. and Gallimore, A. D., "Langmuir Probe Measurements in the Discharge Channel of a 6-kW Hall Thruster", 44th AIAA/ASME/SAE/ASEE Joint Propulsion Conference \& Exhibit, AIAA-2008-4920, Hartford, CT, 21-23 Jul., 2008.

${ }^{23}$ Reid, B. M. and Gallimore, A. D., "Plasma Potential Measurements in the Discharge Channel of a 6-kW Hall Thruster", 44th AIAA/ASME/SAE/ASEE Joint Propulsion Conference \& Exhibit, AIAA-2008-5185, Hartford, CT, 21-23 Jul., 2008.

${ }^{24}$ Shastry, R., Gallimore, A. D., and Hofer, R. R., "Near-Wall Plasma Properties and EEDF Measurements of a 6-kW Hall Thruster", 45th AIAA/ASME/SAE/ASEE Joint Propulsion Conference \& Exhibit, AIAA-2009-5356, Denver, CO, 2-5 Aug., 2009.

${ }^{25}$ Smith, T. B., "Deconvolution of Ion Velocity Distributions from Laser-Induced Fluorescence Spectra of Xenon Electrostatic Thruster Plumes", Ph.D. Dissertation, Aerospace Engineering, University of Michigan, Ann Arbor, MI, 2003.

${ }^{26}$ Shastry, R., Gallimore, A. D., and Hofer, R. R., "Near-Wall Plasma Characterization of a 6-kW Hall Thruster", 31st International Electric Propulsion Conference, 2009-133, Ann Arbor, MI, 20-24 Sep., 2009.

${ }^{27}$ Yim, J. T., "Computational Modeling of Hall Thruster Channel Wall Erosion", Ph.D. Dissertation, Aerospace Engineering, University of Michigan, Ann Arbor, MI, 2008.

${ }^{28}$ Ngom, B. B., Smith, T. B., Huang, W., and Gallimore, A. D., "Numerical Simulation of the Zeeman Effect in Neutral Xenon from NIR Diode-Laser Spectroscopy", Journal of Applied Physics, Vol. 104, No. 2, doi:10.1063/1.2955761, 23 Jul., 2008 , pp. 023303.

${ }^{29}$ Huang, W., Ngom, B. B., and Gallimore, A. D., "Using Nonlinear Zeeman Spectroscopy to obtain In-Situ Magnetic Field Measurement in a Hall Thruster", 31st International Electric Propulsion Conference, 2009-088, Ann Arbor, MI, 20-24 Sep., 2009. 